\title{
The Modalities of Conditionality - Further Considerations
}




\section{INTERNATIONAL MONETARY FUND}

\section{The Modalities of Conditionality—Further Considerations}

Prepared by the Policy Development and Review Department

Approved by Timothy Geithner

January 8, 2002

Contents

Page

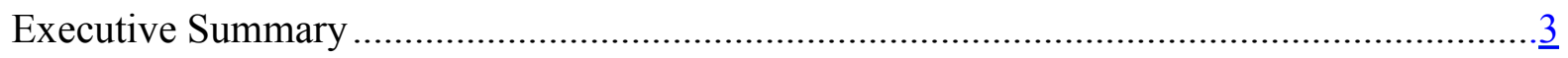

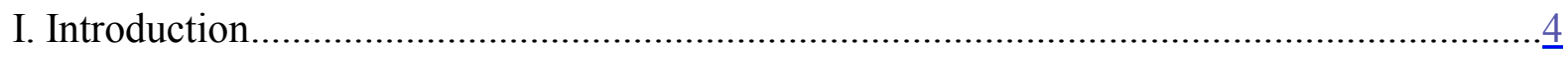

II. Outcome-based Conditionality and Floating Tranche Disbursements .................................

A. Outcomes-Based Conditionality ……………………........................................

B. Floating Tranche Disbursements.....................................................................13

C. Conclusion .................................................................................................

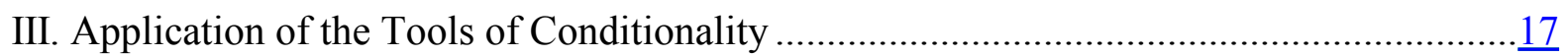

A. Performance Criteria and Waivers .................................................................

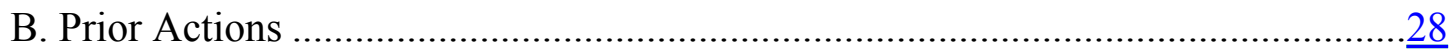

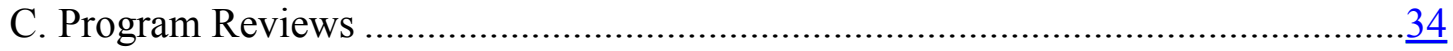

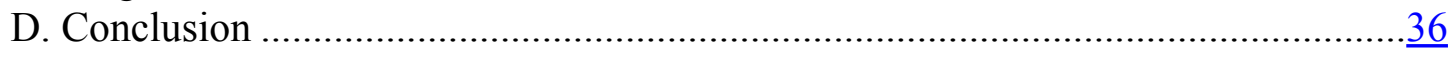

IV. Presentation of Conditionality in Fund Documents.......................................................

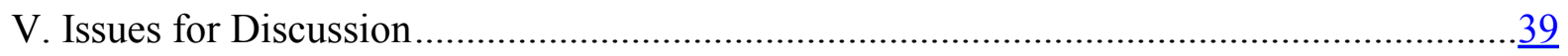

Text Tables

1. Programs With More than 10 Prior Actions in Each Year ..................................................

2. Explicit Adjusters with Respect to Shortfall of External Financing Applicable to the

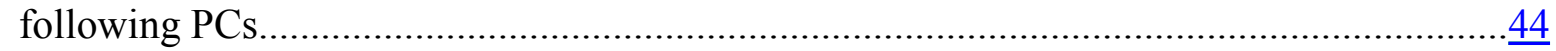

\section{Text Figures}

1. Percentage of Performance Criteria Waived .....................................................................24

2. Structural Performance Criteria: Sectoral Distribution......................................................

3. Distribution of Review Frequencies in Fund-Supported Programs, 1992-2000 …………...37 


\section{Text Boxes}

1. Applying Outcomes-Based Conditionality to the Fund ................................................... 8

2. Outcomes-Based Conditionality and Floating Tranche Disbursements in Other International Financial Institutions

3. Conditionality Under the Enhanced HIPC Initiative.

4. The Fund's Policy on Waivers ............................................................................. $\frac{20}{31}$

5. Survey Results on the Use of Prior Actions.................................................................

6. The Fund's Policy on Financing Assurances ...............................................................

Annex 1 Financing Assurances and Implicit Conditionality ....................................... 40

Annex II Use and Effects of Prior Actions: A Statistical Analysis..................................... $\underline{46}$ 


\section{Executive Summary}

1. This paper examines issues related to the modalities of conditionality, as part of the overall review of conditionality. Specifically, the paper discusses proposals for greater use of outcomes-based conditionality and floating tranche disbursements. It also reviews the use of various tools of conditionality, including performance criteria, prior actions, and program reviews, discussing how these are likely to change in connection with the overall streamlining of conditionality and steps to strengthen ownership.

2. Proposals have been made to base the IMF's conditionality to a greater extent on the achievement of specified outcomes rather than on the implementation of specified actions by the authorities. Outcomes-based conditionality, particularly with regard to structural reforms, could help strengthen ownership by giving the authorities greater flexibility in choosing how to achieve the agreed results, reducing the degree of detail with which the Fund monitors program implementation. The Fund's existing conditionality is in fact a mixture of outcomesand actions-based conditionality. The scope for a further shift, consistent with the need to safeguard the purposes of the Fund's financing, depends on the nature and time frame of the reforms envisaged and their role in the macroeconomic program. In particular, such scope is likely to be greater in the context of PRGF and EFF arrangements-given their medium-term focus on structural reforms - than for standby arrangements.

3. Another prominent proposal has been for the introduction of floating tranches linked to the implementation of specific structural reforms. Floating tranches could give the authorities more room to choose the timetable for implementing reforms, and could thus contribute to ownership. Floating tranches have already been used for HIPC Completion Point disbursements. There is the potential for extending their use in Fund-supported programs, particularly those with more of a medium-term focus. However, with the streamlining of conditionality to concentrate on macro-critical measures, the scope for their use in the Fund's program is likely to remain limited.

4. The paper goes on to discuss the specific tools of conditionality. Here, a key theme is that these basic tools serve distinct and essential roles in the Fund's conditionality, and should continue to be the mainstay of Fund conditionality in the future. In some instances, however, the inappropriate use of these tools may be symptomatic of deeper weaknesses in program design and selectivity, which need to be addressed directly rather than through a reorganization of the conditionality toolkit.

5. One area on which concerns have arisen is in the Fund's policy toward waivers. Waivers are an essential counterpart to performance criteria, providing an element of flexibility in the face of unavoidable uncertainties. Waivers are sometimes an indication of failure and sometimes of successful adaptation to changing circumstances. The use of waivers has increased in recent years, mainly reflecting the higher and increasing incidence of waivers for structural PCs - in contrast to macroeconomic PCs, where no trend is evident. 
While these patterns are partly due to differences in the nature of macroeconomic and structural PCs, they may also reflect a lack of realism in program design, in some instances corresponding to a lack of selectivity. As such, we could expect fewer waivers as conditionality is streamlined and ownership strengthened.

6. Prior actions serve a necessary purpose in getting the initial conditions in place for successful program implementation and they can also underpin the upfront execution of urgent and critical reform measures. But the increasingly widespread use of prior actions as a signal of the authorities' commitment, particularly in cases where past performance has been unsatisfactory, needs further scrutiny. Prior actions do tend to be more numerous in cases where past performance has been weak. But it is questionable that this works in separating committed reformers from those who are not: the analysis of past programs suggests that the number of prior actions does not significantly alter the subsequent success of the program, controlling for the past track record. This argues for greater vigilance in adhering to existing guidelines prescribing parsimony in the use of prior actions.

7. As a related point, the paper discusses the suggestion that the Board be notified formally of all prior actions envisaged in programs currently being discussed with the authorities. It notes that a timely dialogue between Executive directors and staff could be helpful, particularly in cases where some prior actions may be contentious. However, on balance it argues that such a formal procedure could adversely affect country ownership by reducing the staff's ability to adapt prior actions in the course of discussions with the authorities. It is therefore proposed that more systematic use be made of existing informal procedures to keep the Board abreast of possible prior actions such as through the Country Matters sessions.

8. Program reviews have a key role in assessment of program implementation in relation to its objectives. They have become more important with greater uncertainties about macroeconomic developments as well as with the increasing role of structural reforms. Reviews may become even more important as other forms of conditionality - PCs and PAsare used more sparingly, and could be seen as an element of results-based conditionality. Moreover, structural benchmarks need to be more systematically aligned with the focus of the related program review.

9. Conditionality should be presented in staff reports, as well as in LOIs, in a way that brings clarity to the whole framework. This paper suggests that each report should contain a table of performance criteria, prior actions, and the areas on which program reviews will focus, together with any structural benchmarks used to track performance in the latter areas. This presentation would highlight the alignment of benchmarks with reviews.

\section{INTRODUCTION}

10. The IMF's ongoing review of conditionality focuses on several aspects of the linkages between financing and policies. The main objective of this review is to consider possible 
improvements that could strengthen the effectiveness of Fund-supported programs and foster national ownership of these programs, including by focusing and streamlining the conditions attached to the IMF's financing and providing greater clarity to the scope and nature of conditionality. ${ }^{1}$

11. In March 2001, the Executive Board discussed several aspects of conditionality in Fund-supported programs in light of experience over the past decade. This discussion addressed two broad sets of issues. One concerns the coverage of conditionality-i.e. which economic policies are to be subject to conditionality and in particular the process of streamlining conditionality to focus on policies that are critical to the macroeconomic objectives of Fund-supported programs. ${ }^{2}$ Issues related to the coverage of conditionality were considered further on July 25, 2001: in particular, the Board reviewed progress in streamlining conditionality and the role of strengthened Bank-Fund collaboration in achieving that streamlining. A second set of issues concerns what may broadly be characterized as the modalities of conditionality - that is, how the IMF's financing is linked to the implementation of economic policies by member countries, in particular the role of the various tools that are used to monitor the implementation of Fund-supported programsperformance criteria, prior actions, and program reviews, where the latter may also be guided by structural benchmarks. It is important to examine whether these tools of conditionality are suitable for providing assurances to members of their access to the Fund's financing and safeguards that the Fund's resources are being used in line with the purposes of the Fund, while fostering ownership by giving member countries maximum scope to make their own policy choices.

12. In the March 2001 discussion, Directors agreed that these basic instruments of conditionality remain appropriate for Fund-supported programs, and noted the evolution of their application over time. ${ }^{3}$ At the same time, Directors noted a number of issues requiring further consideration by the staff. These included some general proposals to change the form of Fund conditionality, particularly with regard to structural conditionality, in a way that promotes national ownership. One such proposal is outcomes-based conditionality, under which conditionality is based on the accomplishment of specified policy outcomes rather than the implementation of specified policy actions. A second proposal is for floating-tranche disbursements, under which specified tranches of IMF financing would be made available to the country once certain policies have been carried out - in contrast to the existing approach

\footnotetext{
${ }^{1}$ See Concluding Remarks by the Chairman-Conditionality in Fund-Supported Programs Executive Board Meeting 01/23-March 7, 2001 (BUFF/01/36).

${ }^{2}$ The coverage of conditionality is still distinct from the issue of program design.

${ }^{3}$ These issues are examined in Conditionality in Fund-Supported Programs-Policy Issues
} (SM/01/60, Supplement 1, February 20, 2001). 
under which a pre-agreed schedule is set for both policy actions and disbursements. ${ }^{4}$ Both outcomes-based conditionality and floating tranches aim to streamline conditionality and strengthen ownership by giving the authorities greater flexibility in the method and timetable according to which policies are carried out. These modalities have been adopted by a number of other international financial institutions and are proposed for the Fund by a number of observers, including in the external consultations organized as part of the review of conditionality. ${ }^{5}$

13. Other issues raised by Directors pertain to whether the existing tools of conditionality are being applied in a way that is consistent with the overall need to ensure that conditionality is effective while strengthening national ownership. In particular, with regard to performance criteria, several Directors noted that waivers were becoming more frequent, particularly for structural performance criteria, raising the concern that this may reflect either unrealistic expectations in program design, laxity of enforcement, or a proliferation of performance criteria that are not critical to the macroeconomic objectives of the program. If either of these has occurred, it would entail a loss in credibility and also in clarity, as the stated conditions would not accurately indicate what the country is expected to do if it is to continue receiving IMF financing. Directors also noted the rapid increase and diversity across countries in the numbers of prior actions, raising possible issues of uniformity of treatment. A number of Directors, who were concerned that increasing use of prior actions weakened the Executive Board's oversight of the use of Fund resources, favored the systematic provision to the Board of information on prior actions in upcoming programs. Another development requiring further consideration is the increasing frequency and importance of program reviews. While Directors considered this change to be appropriate, they underscored the importance of ensuring that the increasing prevalence of reviews does not unduly weaken member countries' assurances of access to the Fund's resources.

14. The remainder of this paper addresses these issues. Section II discusses the two proposed alternative approaches to conditionality already mentioned, viz. outcome-based conditionality and floating tranches. Section III discusses various issues regarding the application of the existing toolkit for conditionality, including performance criteria and

${ }^{4}$ As discussed in footnote 20 below, outcomes-based conditionality and floating tranches are distinct albeit related concepts.

${ }^{5}$ See Conditionality in Fund-Supported Programs-External Consultations (SM/01/219, Supplement 2, July 17, 2001). See also IMF Conditionality and Country Ownership of Programs by Mohsin S. Khan and Sunil Sharma (WP/01/142, September 2001), a recent IMF working paper that inter alia advocates outcome-based conditionality and floating tranches. See also for example, Carlos Diaz Alejandro, "IMF Conditionality: What Kind?" In PIDE Tidings (January-February 1984), pages 7-9; and Morris Goldstein, IMF Conditionality: How Much is Too Much? (Washington: Institute for International Economics, 2000). 
waivers, prior actions, and reviews. Section IV briefly discusses the presentation of conditionality in Fund documents. Section V presents issues for discussion.

15. Annex I of the paper discusses the role of financing assurances, which Executive Directors asked the staff to examine further in light of the July 25 Board discussion of BankFund Collaboration on Country Programs and Conditionality. ${ }^{6}$ The relevance of this topic stems from concerns expressed by a number of Directors that, notwithstanding the formal accountability of each institution for the use of its own resources, in practice there may be instances in which a country would need to observe the World Bank's (or other institutions') conditionality in order to obtain the IMF's financing. Annex II summarizes preliminary results of an empirical analysis of prior actions.

\section{Outcome-based Conditionality and Floating Tranche Disbursements}

16. Outcomes-based conditionality and floating tranche disbursements both aim to enhance program ownership by giving national authorities greater flexibility in the design and implementation of their adjustment programs - while continuing to serve the purpose of safeguarding the use of Fund resources and providing assurances to member countries of the circumstances under which they will have access to these resources. Each of these is considered in turn.

\section{A. Outcomes-Based Conditionality}

17. One proposal that has gained increasing prominence in recent years is to condition disbursements on outcomes (or "results") rather than on policy actions. ${ }^{7}$ Under such an approach, Fund conditionality would be based on the achievement of specified intermediate

\footnotetext{
${ }^{6}$ See Summing Up by the Chairman: Streamlining Structural Conditionality-Review of Initial Experience; IMF-World Bank Collaboration on Program Conditionality; and Conditionality in Fund-Supported Programs-External Consultations, Executive Board Meeting 01/79, July 27, 2001 (BUFF/01/122). See also Strengthening IMF-World Bank Collaboration on Country Programs and Conditionality (SM/01/219, Supplement 1, Revision 1, August 23, 2001).

${ }^{7}$ For instance, the World Bank is shifting to greater outcomes-based conditionality in some of its lending operations, as are some bilateral donors in providing aid. These examples are not directly comparable, given the distinctive role of IMF financing, but are nonetheless worth considering. See Conditionality in Fund-Supported Programs-Overview SM/01/60, annex III for a discussion; also Goldstein (2000) p. 69; Spraos (1986); Dixit (2000). There is also an extensive literature on outcomes-based conditionality and floating tranches in the context of aid and World Bank financing; this literature is reviewed in SM/01/60, Supplement 1, Annexes II and III, and in SM/01/340.
} 
or final objectives rather than on policy instruments and actions. Monitorable outcomes would be agreed between the national authorities and the Fund, while the precise policy actions taken to achieve these outcomes would be largely left up to the authorities. There are several different kinds of outcomes that could be subject to conditionality (Box 1).

\section{Box 1. Applying Outcomes-Based Conditionality to the Fund}

Much of the discussion of outcomes-based conditionality is framed in very general terms, or in relation to its application to other lending institutions. There are several possible ways of making conditionality outcomes-based, which have different operational implications.

1. One version of outcomes-based conditionality would be pre-selection-i.e. providing financing only to countries that have already accomplished reforms to achieve some minimum standard of good policies and institutions - for example, good governance, strong public administration, central bank transparency, sound banking systems, and/or liberal trade regimes. The Fund's conditionality already incorporates elements of outcomes-based conditionality in this sense: some examples are the use of prior actions to permit a program to be implemented in line with the purposes of the Fund; the requirements for qualification for the Contingent Credit Line (CCL); and the Safeguards Assessments of the legal structure and the control, auditing, and reporting mechanisms of central banks. However, the sequencing of "reforms first-financing later" implied by this approach would limit the Fund's financing of the transitional costs of the reforms and could deny or delay IMF financing to many countries, especially low-income countries or countries trying to cope with external payments crises.

2. A second version would be to link financing to progress in achieving final macroeconomic outcomes such as external balance, inflation, and growth. This would permit a radical streamlining by eliminating conditionality on monetary and fiscal policy as well as all structural conditionality. The authorities would then introduce whatever monetary, fiscal, and structural policies are needed to achieve the macroeconomic outcomes required for the next and subsequent tranches.

3. A third approach would be to identify specific areas of structural policy in which implementation would be monitored on the basis of outcomes rather than on detailed policy action. Here, there are two main sub-variants. One — on which the text of the paper mainly focuses - would be to specify that the result have already been achieved by a certain date, as a condition for continued IMF financing. Another approach would be to monitor progress toward desired results. In both cases, this could be done either in relation to a fixed set of indicators of such progress or by relying on staff's judgment based on all available information. To some extent this is what already happens in program reviews, with structural benchmarks used to track progress.

18. There are four main arguments for outcomes-based conditionality. First, it could help reduce the perception of micro-management of countries' economic policies, by focusing on the overall objectives of policy rather than individual actions. Second, it could help foster and build on country ownership of policy programs, by giving the authorities greater flexibility to design their own economic policies. Third, it reduces the importance of modeling in advance the linkages between policy instruments or actions and outcomes: instead, the authorities 
would be accountable for achieving results and they would thus need to adjust the instruments as frequently as needed to stay on course to these objectives. ${ }^{8}$ Finally, outcomesbased conditionality could reinforce the focus on program objectives, which is a central feature of the conditionality review.

19. In considering the merits of outcomes-based conditionality, it is important to note that the Fund's conditionality is already based partly on outcomes. First, as discussed below, program reviews provide a means for taking stock of progress in relation to broad program objectives rather than myriad policy measures, and agreeing on corrective policies where necessary. Second, many of the quantitative macroeconomic PCs are, in practice, intermediate targets, lying somewhere between policy actions and the desired outcomes: the level of the budget deficit, for instance, though clearly influenced by tax and expenditure policies, also depends on economic activity and revenue performance; similarly, the central bank's net international reserves are typically not under complete policy control. In contrast, conditions on structural reforms have hitherto usually been more at the action-based end of the spectrum. Therefore, much of the debate is centered on the extent to which a more outcomes-based approach to conditionality may be appropriate for structural reforms. ${ }^{9}$ For outcomes-based conditionality to be feasible, one would need to be able to specify outcomes in a reasonably parsimonious way, with sufficient precision to satisfy the legal requirements generally governing PCs in Fund-supported programs (namely that they be both objectively monitorable and meaningful).

20. Before considering whether introducing a greater element of outcomes-based conditionality would be appropriate, it is useful to consider how it might be applied to a number of areas of structural reform. As one example, financial sector reforms involving closing or restructuring insolvent financial institutions could be made conditional on specific outcomes - e.g. that all banks that remain open for business by a specified date would need to have achieved a specific capital adequacy ratio or be supervised under specified proceduresrather than specifying all the reform measures needed to achieve these outcomes. As another illustration, if it the aim is to establish a competitive interbank money market, conditionality could be based on the volumes and bid-ask spreads in that market by a specified date, rather than on the stages of institutional reform needed to establish the market and ensure an adequate degree of competition. As a third example, if the aim is to improve tax collection,

\footnotetext{
${ }^{8}$ As such, it could also reduce reliance on program reviews, since changes in policy needed to achieve previously agreed outcomes could be made by the country without a need to specify these as new PCs or benchmarks.

${ }^{9}$ This is not to suggest that there is no scope for moving further toward outcomes-based conditionality for quantitative performance criteria; recent changes in the conditionality framework for pursuing inflation targeting are a case in point (see Inflation TargetingImplications for Conditionality).
} 
conditionality could focus on targets for revenues collected for a given structure of tax rates rather than on the specific administrative steps needed to achieve this revenue performance. In all these examples-which are intended to be illustrative and not implying an endorsement of their appropriateness - outcomes-based conditionality would give the authorities greater scope to decide how to achieve the intended results.

21. Several considerations are important in deciding the extent to which structural conditionality should be made more outcomes-based. First, outcome-based conditionality in principle makes the authorities accountable for achieving outcomes that are less than fully under their control. In principle, it shifts the risk of exogenous shocks or "model errors" to the borrowing country, so that even if the authorities follow policies that may reasonably be expected to achieve the desired outcomes, the objectives may be missed because of exogenous shocks or because the assumed model linking policies to outcomes is misspecified. Under actions-based conditionality, the Fund would still disburse the next tranche of financing as long as the authorities had carried out the policy actions that had been agreed ex ante; under outcomes-based conditionality it would not. ${ }^{10}$ This could also, in some cases, make the Fund's lending pro-cyclical, as adverse shocks would impede a country's ability to achieve the targeted outcomes. For outcomes-based conditionality to be workable, the authorities would need to accept that greater flexibility comes at the cost of greater risk. The Fund would also need to recognize that making the country partly responsible for achieving the outcome, and not just for taking the envisaged actions, would strengthen the authorities' incentive to achieve the outcome. ${ }^{11}$

22. Second, outcomes-based conditionality must be designed in a way that avoids a situation in which the authorities achieve the specified objectives by unsustainable or inappropriate policies. This is particularly clear in the case of macroeconomic measuressuch as closing a budget deficit by raising tariffs or by cutting essential social expenditures. But it also applies to structural measures - for instance, a financial sector reform that is

${ }^{10}$ Of course, the Fund could grant waivers in such cases, but if the granting of waivers were conditional on the authorities' having followed prudent policies, then, effectively, conditionality would be back to being action-based. But the reverse may also be true, since the Fund is more likely to grant a waiver for failing to implement a specified action if the overall outcome is achieved.

${ }^{11}$ This can be seen in terms of a simple principal-agent model under asymmetrical information. Suppose that the outcome depends on actions by the country which can only imperfectly be monitored by the IFI, and an imperfectly observable exogenous shock. There is then a tradeoff between incentives and risk-sharing; the optimal contract bases the provision of financing on both outcomes and actions and leaves the country bearing some of the risk. See also Strengthening Country Ownership of Fund-Supported Programs (SM/01/340, November 13, 2001), footnote 10. 
implemented in a way that protects political insiders or leaves important vulnerabilities; or a tax revenue collection target that is met by holding up VAT refunds or offering a tax amnesty. To the extent that objectives are achieved by inappropriate, short term-oriented policies, this could jeopardize Fund resources, as Fund credit would be outstanding long after the end of the program. In principle, such considerations could be captured by specifying the desired outcomes sufficiently comprehensively. Yet explicitly proscribing inappropriate policies in a sufficiently comprehensive manner may in some cases be more intrusive than reaching agreement between the Fund and the authorities on appropriate policy actions and making the implementation of the actions a condition for the Fund's financing. Outcomesbased conditionality is thus more likely to be appropriate in situations in which there exist more than one means of achieving a particular objective that are acceptable from the Fund's standpoint.

23. Finally, because policies - particularly structural reform measures - take time to come to fruition, and because "outcome" variables in many cases involve longer reporting lags than actions, applying outcome-based conditionality to much or most of the policy content of a Fund-supported program may introduce a tension between effective oversight of policy actions and the timing of disbursements. ${ }^{12}$

24. These considerations suggest that in practice it will likely be necessary to blend outcomes-based conditionality with elements of actions-based conditionality. The extent to which it would be appropriate to make greater use of outcomes-based conditionality in Fundsupported programs would depend on the nature and objectives of the program and the role envisaged for particular policies in achieving those objectives. While all Fund-supported programs share the basic objective of achieving or maintaining medium-term external viability, the focus of other objectives, such as restoring market confidence, or improving efficiency and achieving long-term sustained growth, differs across programs.

25. At one extreme are Fund-supported programs in capital account crisis countries, where the key focus of the program is restoring confidence and capital inflows. The logic of program design in these cases may require up-front disbursements of substantial amounts of official financing, whereas the structural reforms designed to underpin the program and to restore market confidence — such as those in the financial or corporate sectors - may take significantly longer to produce measurable outcomes. If the program is successful, by the time outcomes on structural reforms could be observed the associated disbursements should be largely superfluous (since there would have been a resumption of private capital inflows

\footnotetext{
${ }^{12}$ For instance, there would be the issue of how to link a continuous flow of IMF financing to measurable results that are achieved only at discrete intervals, even though the country is fully implementing the policies called for under the program. These issues are discussed in Conditionality in Fund-Supported Programs-Policy Issues (SM/01/60, Supplement 1, February 20, 2001).
} 
and thus likely no longer a balance-of-payments need). Similar considerations apply, albeit to a lesser degree, to countries experiencing more traditional macroeconomic imbalances. It is likely that in such cases conditionality would need to be based mainly on an assessment of progress toward outcomes, rather than their realization. Such an assessment may need to be partly actions-based, given the limited information that may be available on intermediate outcomes. Moreover, in such cases actions-based conditionality may be useful inasmuch as it lays out the structural reform agenda (and conditions disbursements on the authorities' adopting the specified measures), thereby contributing to confidence in the program. ${ }^{13}$

26. At the other end of the spectrum are programs, whether supported by PRGF or other facilities, that include structural reforms aimed at medium-term sustainability and growth rather than at addressing an immediate macroeconomic crisis. In many such cases, the Fund may be in the role of providing continuing financial support for a rolling reform agenda, with some reforms being brought to completion while others are being initiated. In some such cases, key reforms - such as to governance, or to the financial system - may also increase the country's ability to make effective use of external financing. In this context, the tension between the timing of financing needs and the completion of reforms may be less acute. Such cases are most likely to be suitable for a greater shift in the direction of results-based conditionality.

27. In conclusion, there are both advantages and risks to shifting toward the outcomesbased end of the conditionality spectrum, but on balance, there is scope for greater reliance on outcomes-based conditionality for some types of structural measures.

28. In addition, there are steps, short of outcomes-based conditionality, that could serve the same objectives of focusing attention on the end result and eschewing micromanagement. In particular, recent efforts at streamlining conditionality have aimed to reduce the congestion of detailed instrument prescriptions, such as those involved in specifying numerous structural benchmarks to introduce a VAT rather than specifying the introduction of the VAT as an outcome. The increasing importance of program reviews in recent years, as discussed below, can also be viewed as a shift along the spectrum toward outcomes-based conditionality, to the extent that it focuses on progress in relation to overall objectives. ${ }^{14}$

${ }^{13}$ For further discussion, see IMF-Supported Programs in Capital Account Crises-Design and Experience (SM/01/245, August 3, 2001).

${ }^{14}$ As an example, the Board has approved a reviews-based approach to monetary policy conditionality for countries pursuing inflation targets. Under this approach, conditionality would be based, not on the inflation outturn, but on an assessment of whether current policies are on track to achieve the inflation target over the medium term. See BUFF/00/11, Inflation Targeting-Implications for IMF Conditionality, January 24, 2000. See also SM/99/296, $12 / 14 / 99$, the staff paper on which this discussion was based. 


\section{B. Floating Tranche Disbursements}

29. Another proposal for giving the authorities greater flexibility in program

implementation is to allow for "floating tranches," with disbursements made not according to a fixed schedule but only once certain policy actions have been undertaken or program outcomes achieved. ${ }^{15}$ By allowing for greater flexibility in the timing of structural reform measures, floating tranche disbursements could foster greater ownership. Such floating tranche conditionality (and associated disbursements) have been adopted, inter alia, by the World Bank, including in the context of Higher Impact Adjustment Lending (HIAL), with generally positive results (Box 2).

30. In some specific circumstances, Fund arrangements have also featured disbursements that effectively float. For instance, under the Fund's involvement in the Debt Strategy associated with the Brady Plan in the late 1980s, set-asides and augmentations were made available at the time of a debt reduction operation, in order to help finance it, with the precise timing of the operation left unspecified. ${ }^{16}$ More recently, the completion point for debt relief under the HIPC Initiative is based on a set of floating conditions (see Box 3). Less benignly, disbursements sometimes de facto "float" to the extent that program reviews - and associated purchases - are delayed in relation to their original schedule. Indeed, historically, about twothirds of all reviews have been delayed by over one month, and over a third by more than four months, from the original schedule. Arguably this may amount to a situation in which the country receives financing only after it has implemented certain reforms - either as set out in the original program or introduced subsequently as corrective action for missed targets. ${ }^{17}$ The question, therefore, is whether there may be a case for explicit floating tranche disbursements in Fund arrangements. If so, this could be done by indicating in the arrangement that specific tranches will be made available to the member whenever specified reforms have been completed.

${ }^{15}$ It is worth emphasizing that outcomes-based and floating tranche conditionality are distinct concepts. It is possible to have outcome-based conditionality according to a fixed schedule or, conversely, policy-based conditionality according to floating tranches. In practice, however, the circumstances under which outcomes-based conditionality and floating tranche conditionality might be appropriate are likely to be similar.

${ }^{16}$ Chairman's Summing Up on Fund Involvement in Debt Strategy SM/89/61.

${ }^{17}$ Similarly, the use of prior actions - whereby a program does not go to the Fund's Executive Board for approval until certain prior actions have been implemented - may mean that the timing of IMF financing effectively floats. 


\section{Box 2. Outcomes-Based Conditionality and Floating Tranche Disbursements in Other International Financial Institutions}

Other international financial institutions have adopted some elements of outcomes-based conditionality and/or floating tranche disbursements. While the circumstances are not strictly comparable to those of IMF-supported programs, the experience is relevant.

The World Bank has substantial recent experience with outcomes-based conditionality and floating tranches as design features that enhance government ownership by aligning disbursements with reform readiness. An example is the World Bank's Higher Impact Adjustment Lending (HIAL) initiative introduced in the Africa Region in 1995. The initiative was based on two modifications to the traditional lending model: first, greater country selectivity and, second, more flexible design of lending programs. The countries were pre-selected based on the Bank's Country Performance Ratings (CPR), with a view to ensuring better-than-average commitment of the authorities to the reform program and wider stakeholder consultation, while their overall, pre-HIAL performance was broadly comparable to that of other countries in the region. Those countries were then given more flexible arrangements, including floating tranches (nine of 21 operations in 17 countries in the sample reviewed in the 1999 World Bank Operations Evaluation Department Study), increased freedom in timing their reforms, and fewer conditions (21 on average as compared to the sub-Saharan African (SSA) average of 38 per adjustment operation during 1980-93). A 1999 World Bank evaluation found that macroeconomic performance under the HIAL was better than the IDA comparator groups, other non-HIAL subSaharan countries and non-sub-Saharan countries. The extent of progress during the HIAL period (1996-98) also compared favorably with the pre-HIAL period (1993-95). ${ }^{1}$ The more recent review of the Bank's experience with adjustment lending in the Adjustment Lending Retrospective ${ }^{2}$ also concluded that floating tranches can be a useful approach for discrete reforms with uncertain timing, such as privatization of public enterprises.

Recently, two other international financial institutions started experimenting with lending instruments that contain some elements of results-based conditionality. The Asian Development Bank (ADB) initiated the so-called "Program Cluster Approach" (PCA) in late 1999. ${ }^{3}$ This instrument has frequent floating tranches (as opposed to the typical ADB two-tranche arrangement), countries would pre-qualify by their past track record, and an assessment of a satisfactory progress toward the ultimate goal would compensate for missing some of the detailed conditions. The Inter-American Development Bank (IADB) approved in late 2000 a pilot project for "Guarantee Disbursement Loans.", A country would have an option of choosing either a traditional, multiple-tranche arrangement or a guarantee available upfront, approval and extension of which would be based on the assessment of past results. Given the short period in which the ADB and IADB instruments have been in existence, no evaluation of their performance is available.

1/ World Bank, 1999, "Higher Impact Adjustment Lending (HIAL): Initial Evaluation," OED, (World Bank: Washington, D.C.). See also World Bank, 1999, "1999 Annual Review of Development Effectiveness," (World Bank: Washington, D.C.).

2/ See World Bank, 2001, Adjustment Lending Retrospective, available at: www.worldbank.org/about/whatwedo/projects.htm

3/ See Asian Development Bank, 1999, "Review of ADB's Program Lending Policies," www.adb.org/Documents/Program_Lending/1999/prog0000.asp and Asian Development Bank, 2001, "Special Evaluation Study on Program Lending," www.adb.org/Documents/PERs/sst_stu200116.pdf.

4/ See Inter-American Development Bank, "Pilot Program to Provide the Option of Disbursing Loans in the Form of a Guarantee," www.iadb.org/EXR/pdf/GUA1A.pdf. 


\section{Box 3. Conditionality Under the Enhanced HIPC Initiative}

The approval of the Enhanced HIPC Initiative in the fall of 1999 marked a shift toward a more flexible conditionality. In place of the original three-year interim period, a floating completion point was introduced, linked to the achievement of specified targets at any time after the decision point.

HIPC conditionality for reaching the decision point, and hence achieving access to interim relief, is based mainly on the track record of performance up to the decision point, as established under Bank and Fund supported programs. Conditionality at the completion point includes the following key elements: (i) continued sound macroeconomic performance, as monitored under the PRGF; (ii) preparation of a PRSP and first annual progress report thereunder (except for retroactive cases); and (iii) satisfactory implementation of a set of specific actions and/or policy reforms as specified in the decision point document. The latter typically include selected structural reforms (such as public expenditure management, privatization, and banking sector reforms); and social policy and poverty reduction requirements (such as increases in health and education spending and other indicators of the services being provided in those areas). Floating completion points ensure that the recipient countries have more control over the process and the completion point is reached as soon as the set preconditions are met.

31. Floating tranche disbursements would clearly not be appropriate for macroeconomic variables or for structural measures that are required for immediate macroeconomic stabilization, since the timing of these measures is essential to the short-run macroeconomic framework. For instance, a tax measure that is adequate for closing the fiscal gap if introduced at the beginning of the year may no longer be an adequate policy response if delayed until the end of the year. ${ }^{18}$ Floating tranches may, however, be useful for some measures that are included under conditionality on the basis of their importance for mediumterm external sustainability and growth. In this case, the Fund's overall disbursements could theoretically be split into two components - a "macroeconomic" component according to a traditional fixed schedule, and a second component, associated with specific structural reforms, which could be subject to floating disbursements. ${ }^{19}$ The policies linked to the fixedtranche component would need to constitute a viable, albeit not first-best, program even if the

\footnotetext{
${ }^{18}$ Moreover, fiscal measures are often linked to specific time-bound events such as the presentation of the budget or parliamentary sessions.

${ }^{19}$ For instance, in some countries financial sector reforms may not be immediately critical for achieving macroeconomic stability, making reforms in this area a candidate for floating tranche conditionality. This is more likely to be the case for financial sector liberalization than for reforms needed to deal with major financial sector weaknesses, though.
} 
policies linked to floating tranches were not implemented; floating tranches would only be made available to the country if this fixed-tranche sub-program remained on track. ${ }^{20}$

32. Given the basic purpose of the Fund, floating tranche conditionality is most likely to be appropriate in cases in which the achievement of a particular reform or reforms itself generates identifiable temporary balance of payments financing need. ${ }^{21}$ Floating tranches are also most likely to be desirable either if there is some unavoidable uncertainty about the timing with which a measure can be accomplished or that for some reason it is desirable for the authorities not to make an up-front commitment on timing - otherwise it would make more sense for the authorities to agree with the staff on a realistic timetable and commit themselves to that timetable, using program reviews or waivers to take account of any circumstantial deviations from the timetable envisaged. As a possible illustration, consider a major trade liberalization that in the medium-term is expected to help diversify the economy and reduce its vulnerability to shocks, but entails an increase in imports that will only gradually be offset by increased exports. If the timing of such a measure - associated with domestic political processes - is also difficult to predict, a floating tranche may be a suitable way of financing such short-term costs. The use of floating tranches is particularly likely to be appropriate in PRGF arrangements, given those arrangements greater orientation toward medium-term growth and poverty reduction.

33. While floating tranches may be a suitable way of providing financing for some economic policies, the set of policies for which floating tranches would be appropriate is likely to shrink as conditionality is streamlined to focus on those measures that are critical to the macroeconomic objectives of the program. Measures that are indeed critical are also likely to be those whose timing is more sensitive than measures that are only viewed as broadly desirable. For example, in some cases key tax reform measures need to be implemented by a certain date in order to achieve the program's fiscal objectives. In some cases - for instance, with major financial sector restructurings - timely action may be needed to prevent the situation unraveling further. There are also, in many cases, issues of sequencing: for instance, new bankruptcy legislation may need to be in place before debt restructuring can be undertaken successfully. Floating tranches are less likely to be suitable for such measures. In contrast, structural measures that advocated as broadly desirable, such as reforms in marketing arrangements that do not have a major fiscal impact, are less timesensitive and thus are more likely to be suitable for floating tranches - but it is with regard to such measures that conditionality is to be curtailed.

\footnotetext{
${ }^{20}$ It would also be the fixed-tranche sub-program component that other creditors would take into account in determining whether the Fund-supported program was on- or off-track.

${ }^{21}$ This was the case, for instance, with the debt-reduction operations financed under the Fund's Debt Strategy.
} 


\section{Conclusion}

34. This discussion suggests that some move toward both outcomes-based conditionality and floating tranche disbursements would be feasible, and in some cases, desirable. The applicability of both of these approaches depends on the nature of the reforms envisaged and their place in the overall framework of the program. Both of these approaches to conditionality are more likely to be appropriate with regard to policy measures whose implications for conditionality pertains to medium term macroeconomic objectives rather than to the requirements for immediate stabilization. As such, they are likely to play a significant role in PRGF arrangements - with their emphasis on poverty reduction and growth, and their emphasis on building ownership through a consultative process within the country - and to a lesser extent in EFF arrangements; they likely to play a less important role in SBAs, but even here there may be some scope for adopting these techniques. In cases in which the adoption of such techniques is judged to be consistent with adequate safeguards for Fund resources, it should be discussed fully with the authorities, to ensure that they are fully seized of the implications, including the tradeoff between flexibility and assurances of access to Fund resources.

\section{Application of The ToOls of Conditionality}

35. The Fund's present set of tools for conditionality has gradually evolved from its earliest days of operation to meet the needs of the institution and its members. Each of these tools provides a specific way of linking IMF financing to policy implementation. Performance criteria are the oldest of these tools, introduced in the 1950s. A performance criterion (PC) specifies either a quantitative target to be met or a policy action to be implemented by an agreed date (or in some cases, continuously over a specified period) for the country to be able to continue to draw on the IMF's financing. If the PC is not observed, this does not necessarily bar the country from financing, but triggers consideration of whether or under what circumstances a waiver could be granted. ${ }^{22}$ A prior action (PA) differs in time frame, in the element of flexibility provided, and in their effects: a set of prior actions, to be implemented before the program is considered by the Executive Board, is agreed between the staff and management and the authorities, and if not implemented, do not automatically interrupt purchases. Prior actions are often specified during the course of discussions of the program approval or review to which they pertain, and the process of negotiation enables current economic circumstances to be taken into account in their specification. Since the 1960s, the Fund has also used program reviews to set performance criteria for the future life of the program as well as to assess performance in particular policy areas. Since the 1980s,

${ }^{22}$ Conversely, meeting all the PCs is not always sufficient for continued access to Fund resources. Where purchases are also conditioned on completion of a program review, the completion of the review may also depend on satisfactory progress in broader policy areas, as set out in the program documentation. 
reviews have often been guided by structural benchmarks (SBs) which may be used to define the contours of a review by laying out a set of envisaged steps in policy implementation; however, meeting these SBs is neither a necessary nor a sufficient condition for completing the review. Indicative targets are in some cases a quantitative analogue of structural benchmarks, which provide an indication of progress toward ultimate objectives; in many cases, these targets are specified as PCs in light of more reliable information. All of these tools of conditionality are in some sense signal extraction mechanisms, which in different ways trigger policy corrections when this is needed in response to new information. The basic purposes and rationale of these tools are discussed in an earlier policy paper, ${ }^{23}$ the present paper goes on to address some particular issues and concerns.

36. The existing tools of conditionality need to be seen in the context of the 1979 Guidelines on Conditionality. In particular, those Guidelines specify that the adjustment program "will pay due regard to the domestic social and political circumstances, the economic priorities, and the circumstances of members" ( $\mid 4)$. They also specify that the Managing Director will recommend that the Executive Board approve a member's request for resources only "when it is his judgment that the program...will be carried out" (\7). These requirements together imply some degree of national ownership of programs, selectivity of the countries recommended for access to the Fund's resources, and realism in program design.

37. But as discussed in the recent paper on program ownership, ${ }^{24}$ in practice national ownership, selectivity, and design realism may in some respects be incomplete. There are several reasons this might be the case: for instance ownership may need to be built over time, starting from a relatively narrow base of support within the country; or the Fund may approve financing for systemic or other reasons while reasonable doubts remain about the breadth and depth of country commitment or the chances of success. Under such circumstances, there may be an attempt to use the tools of conditionality to compensate for these other deficiencies, and the degree of flexibility in these tools of conditionality may become a weakness. In particular, some critics see the Fund as pressing countries to agree to ambitious programs that it does not expect to be implemented, in order to obtain leverage over the countries' policies or because of an excessively short-term focus on program approval. In either case, the degree of flexibility offered by conditionality - the ability to grant waivers, the element of judgment in program reviews - may make the Fund more likely to propose unrealistic programs and the authorities more willing to agree to them.

${ }^{23}$ Conditionality in Fund-Supported Programs-Policy Issues (SM/01/60, Supplement 1, February 20, 2001).

${ }^{24}$ Strengthening Country Ownership of Fund-Supported Programs, SM/01/340, November 13, 2001. 
38. It would be useful to gauge to what extent these concerns, which have been raised both within and outside the Fund, are borne out by the experience of Fund programs. This is important, not only with regard to these tools themselves, but also as an indication of how the application of these tools is likely to change as the Fund moves to refocus and streamline its conditionality and strengthen national ownership.

\section{A. Performance Criteria and Waivers}

39. Performance criteria (PCs) give countries some assurance of access to the Fund's resources, provided that certain key policy variables and actions follow their envisaged paths. $^{25}$ Their role as a signal extraction mechanism is in triggering a reassessment of policies when these variables or actions fail to meet the specified criteria. The possibility of waivers gives an essential element of flexibility to the application of PCs (Box 4), giving the Fund scope to reassess policies when PCs are not met. In many cases, such a reassessment indicates the need for adjustments in policies, in which case the Fund's financing can continue on the basis of corrective action. In other cases where the nonobservance of the PC was minor or was due to a flaw in the design of the original program, the Fund's financing may be able to continue without corrective action.

40. The need for waivers can be seen most clearly in relation to macroeconomic performance criteria. Consider, for instance, a PC on credit to government. While the main purpose of such a PC is to ensure that the Fund does not continue to provide financing for a country unless the authorities are continuing to implement steps envisaged to tackle fiscal imbalances that may be the underlying source of external payments difficulties, a country could in fact miss such a PC for any of a variety of reasons: for instance, the authorities may be failing to implement agreed tax and expenditure measures; macroeconomic developments may have turned out less favorable than forecast, resulting in lower-than-expected tax revenues; or tax elasticities estimated by the staff and used as the basis for program projections of revenues may turn out to have been incorrect. Depending on which of these explanations is valid, the appropriate response - adjusting the targets or asking the authorities to take additional measures in the context of a waiver, or stopping the Fund's financing-will differ. Similar considerations apply, mutatis mutandis, to structural performance criteria, where the decision on whether to grant a waiver must evaluate the seriousness of the nonobservance, the circumstances, and any corrective action taken by the authorities.

${ }^{25}$ This assurance is not complete since even if all PCs are observed, access in many cases also depends on successful completion of a program review. 


\section{Box 4. The Fund's Policy on Waivers}

The policy on waivers and modification of PCs is a well established feature of upper credit tranche arrangements, which has been periodically discussed by the Board. ${ }^{1}$ This policy is implicitly inscribed in the text of every Fund arrangement. The paragraph setting the PCs includes a clause which provides that should any of the PCs be missed, "purchases will be resumed only after consultation has taken place between the Fund and member and understandings have been reached regarding the circumstances in which such purchases can be resumed." The term "understandings" refers, although is not limited to, the circumstances under which the Executive Board may grant a waiver of a PC that was not observed.

In stand-by or extended arrangements, purchases are cumulative and only the most recent quantitative PCs needs to be observed, or their observance or applicability waived, to permit all scheduled purchases up to that date to be made. In contrast, in PRGFs all missed PCs must be waived for all disbursements to be made, since each disbursement is conditioned on a separate set of criteria. Structural PCs in GRA arrangements must be made for any purchases to be made after the test date. In PRGF arrangements, structural PCs must be observed or waived for the purchases or disbursements to which they apply to be made. Any delay in implementation, no matter how short, would therefore result in nonobservance of the structural PCs and requires a waiver. ${ }^{3}$ The nonobservance of conditions that are binding at all times, i.e., continuous PCs (e.g. the non-accumulation of external arrears or the non-intensification of exchange or trade restrictions for BOP purposes) also requires a waiver, even when the discrepancy is rapidly reversed.

Earlier Executive Board papers describe waivers to be “... appropriate for dealing with minor ex post (original emphasis) deviations from PCs, that is, with deviations that did not represent departures from agreed policies and that were considered to be of a temporary or reversible nature: modifications would be appropriate when departures from PCs were expected to occur because of the failure of basic program assumptions to materialize or of the emergence of developments that had not been anticipated at the inception of the program."

However, there are limits to the appropriateness of waivers: “.. where major assumptions underlying a program or policies are significantly changed and/or when deviations from initial policy intentions have been very significant, in order to preserve both the Fund's and the member's credibility a new program under a new arrangement with different targets will generally be preferable to attempts at rescuing arrangements through modifications."

1/ "Waivers and Modifications of Performance Criteria in Upper Credit Tranche Arrangements - Fund Experience, 1974-80, (EBS/81/70), March 23, 1981, Pg. 2

2/ Stand-by and Extended Arrangements-Standard Forms (10564-(93/130)

3/ There are three types of waivers: waivers of non-observance, waivers of applicability, and waivers for noncomplying purchases on account of misreporting. Waivers of non-observance allow the country to make a purchase despite having failed to observe a PC for that purchase. Waivers of applicability are employed in reviews delayed past a new test date for which all data are not yet available. There are no waivers of applicability in PRGF arrangements since here the rights to draw do not accumulate. Waivers for noncomplying purchases eliminates the expectation of early repurchases of these purchases under the Fund's guidelines on corrective action with respect to noncomplying purchases. The discussion in the text is limited to waivers for the nonobservance of quantitative, structural or continuous PCs.

4/ Waivers and Modifications of Performance Criteria in Upper Credit Tranche Arrangements - Fund Experience, 1974-80”, (EBS/81/70), March 23, 1981, Pg. 2

5/ "Review of Upper Credit Tranche Stand-By Arrangements Approved in 1978-79 and Some Issues Related to Conditionality", (EBS/81/152), July 14, 1981, Pg. 22 
41. In this framework, the incidence of waivers depends on several factors: the design of the program - for instance, on how ambitious is the policy agenda — and the specific set of PCs used to monitor its implementation. The latter in turn involves a tradeoff related to the signaling role of PCs mentioned earlier: specifying more PCs and allowing smaller margins for design error and for slippages tends to increase the probability that, in the event that implementation is deficient, a policy reassessment and appropriate corrective action will be triggered. But at the same time, more detailed monitoring also increases the probability of false alarms, whereby a PC is missed and a reassessment is undertaken unnecessarily-with the effect of weakening the country's assurance of access to the Fund's resources. ${ }^{26}$ The frequency of test dates for performance criteria can be analyzed on the same basis: ${ }^{27}$ less frequent test dates would reduce the probability of a PC's being missed and a waiver needed, but this would come at the cost of allowing a program to go further off track before a reassessment of policies is triggered. The policy toward granting waivers, especially on the basis of planned corrective action by the authorities, also involves a tradeoff: a more liberal policy toward granting waivers would increase the risk that the Fund continues its financing when policies are not on track to achieve its targets, while a grudging policy toward waivers would increase the countervailing risk of withdrawing support for a potentially successful program.

42. This logic suggests that the frequency with which waivers are granted would reflect various factors affecting the configuration of PCs and the degree of uncertainty associated with each one. Although under existing policies all PCs are, in principle, supposed to be under the control of the authorities, macroeconomic PCs such as base money or net international reserves are typically not expected to be controlled directly, while structural PCs may be subject to uncertainties associated with political processes. The degree of uncertainty associated with particular PCs may also change over time: for instance, the uncertainty associated with the central bank's Net Domestic Assets (NDA) increased as central banks stopped applying quantitative credit controls and began implementing monetary policy through market-based instruments. Such PCs would also have become more uncertain as

\footnotetext{
${ }^{26}$ In practice, another option may be to specify policy measures as structural benchmarks. Since SBs only map out the contours of a program review, and no specific grounds must be provided for completing a review when a particular SB has not been met, it provides a less insistent signal when policies are off-track - in effect, a quieter warning bell, which is an advantage when there is a false alarm but correspondingly disadvantageous when there is a fire. This is not suitable for measures that are individually critical to the success of the program, but may be used for key steps toward important policy outcomes.

${ }^{27}$ The discussion in this paragraph considers the tradeoffs abstracting from the constraints of existing policies. Under existing policies, the frequency of test dates in SBAs and EFFs is at least quarterly, with the possibility of more frequent test dates only under special circumstances (especially in high-access cases).
} 
globalized capital markets increase the degree of uncertainty associated with certain key macroeconomic relationships such as demand for money. It should thus be no surprise that the frequency of waivers differs across types of conditions and varies over time.

43. In contrast to this view of waivers as a device for allowing a program to adapt to changing circumstances to achieve its objectives, concerns have been expressed that waivers have too often been used to salvage programs in the face of major policy slippages that are not fully compensated by corrective action but necessitate a significant weakening of program objectives. Such policy slippages may have been unforeseeable; in such cases, granting waivers may be seen as a pragmatic alternative to the de facto suspension or outright cancellation of arrangements - which may appear sensible in the context of a particular country but chips away at the credibility of Fund-supported programs. Another concern is with regard to a possible situation in which program design is unrealistic to begin with either from the standpoint of the macroeconomic scenarios underlying the objectives or the authorities' commitment to implement the program. If this is the case, it is the Fund's willingness to grant waivers that encourages programs to be designed unrealistically, and makes the authorities less likely to resist signing on to a program that they cannot implement. A particular concern has been raised with regard to structural PCs: that programs have been overloaded with structural conditions that are not really critical to program objectives and are not likely to be implemented. If this happens, it would result in a loss of clarity about conditionality, since the authorities would not really be expected to implement all the conditions specified to receive the IMF's financing.

44. Are these concerns well-founded? The experience sheds some light on this question, but it is not conclusive. Requests for waivers and modifications of PCs have been rising at least since the mid-1970s. A 1981 staff paper on waivers and modification indicated that "... requests for waivers and modification of PCs in absolute terms show a rapidly increasing trend over the last seven years (1974-1980). ${ }^{, 28}$ A later Board paper illustrates a steady increase in the share of total arrangements with waivers or modifications from 1974 of about 23 percent of all SBAs and EFFs to about 70 percent in $1990 .{ }^{29}$ However, in both cases, much of the increase reflected an increase in the average length of arrangements, as well as in the number of conditions. Nonetheless, the implementation of the Fund's policy on waivers has been a recurring concern of the Executive Board. One particular concern that some Directors have voiced recently is that more waivers have been requested — and granted - for missed structural PCs than for quantitative PCs.

\footnotetext{
28 "Waivers and Modifications of Performance Criteria in Upper Credit Tranche Arrangements-Fund Experience, 1974-80”, (EBS/81/70), March 23, 1981, Pg. 4.

29 'Ovverview of Developments in Countries with Stand-By and Extended Arrangements Approved During 1988-91, (EBS/94/104), May 19, 1994, pg. 60a.
} 
45. The experience over the period $1987-2000^{30}$ shows that both the total number of requests, and the number of requests per test date, for waivers of nonobservance on quantitative, structural, and continuous PCs, have continued to rise. This is, in part, associated with the rising number of PCs. At the same time, it is important to consider trends in the percentage of performance criteria waived (Figure 1). The proportion of quantitative PCs waived has not displayed any clear trend over the past decade, after a sharp increase in 1990, from about 2 percent to almost 5 percent. The proportion of quantitative PCs in ESAF/PRGF arrangements that are waived has tended to run consistently higher: about 10 percent of quantitative PCs in these arrangements are waived. Given this greater incidence of waivers in ESAF/PRGF arrangements, the increase in the overall share of quantitative PCs waived at the beginning of the 1990s reflects, in part, the increased proportion of ESAF/PRGF arrangements in all Fund arrangements. This raises the question, in turn, of why the incidence of waivers is higher in ESAF/PRGF arrangements: it may in part reflect greater uncertainty and lower data quality for low-income countries; but some other factors may be at play.

46. In contrast, trends in waivers for structural PCs have been much more marked (Figure 1, bottom panel). The proportion of such PCs waived reached a peak in 1995 of almost 45 percent (almost 65 percent for EFFs), before declining sharply in 1996; since then, about 25-30 percent of structural performance criteria have been waived, with no clear ranking between arrangements. It is also noteworthy that structural PCs outside the Fund's core areas of responsibility and expertise have a higher incidence of being missed and waived (Figure 2) than those in the core areas, ${ }^{31}$ suggesting that such PCs were less likely to be viewed as being of "make-or-break" significance for the program. Care should be taken in interpreting these data, given the small numbers of PCs in non-core areas.

\footnotetext{
${ }^{30}$ The methodology adopted here is not directly comparable to those of earlier studies. While in earlier studies the number of arrangements where one or more waivers and/or modifications occurred was examined, the present study investigates the number of waivers for each test date in each program. This allows for an explicit accounting for changes in the length of arrangements and the frequency of test dates.

${ }^{31}$ Most waivers, of course, are granted for PCs within the Fund's core areas, as PCs in the core areas represent the lion's share of all structural PCs. For these purposes, the Fund's core areas are defined to include fiscal, financial sector, and trade and exchange rate systems, although responsibility for policy advice in each of these areas is in fact shared with the World Bank.
} 
Figure 1. Percentage of Performance Criteria Waived
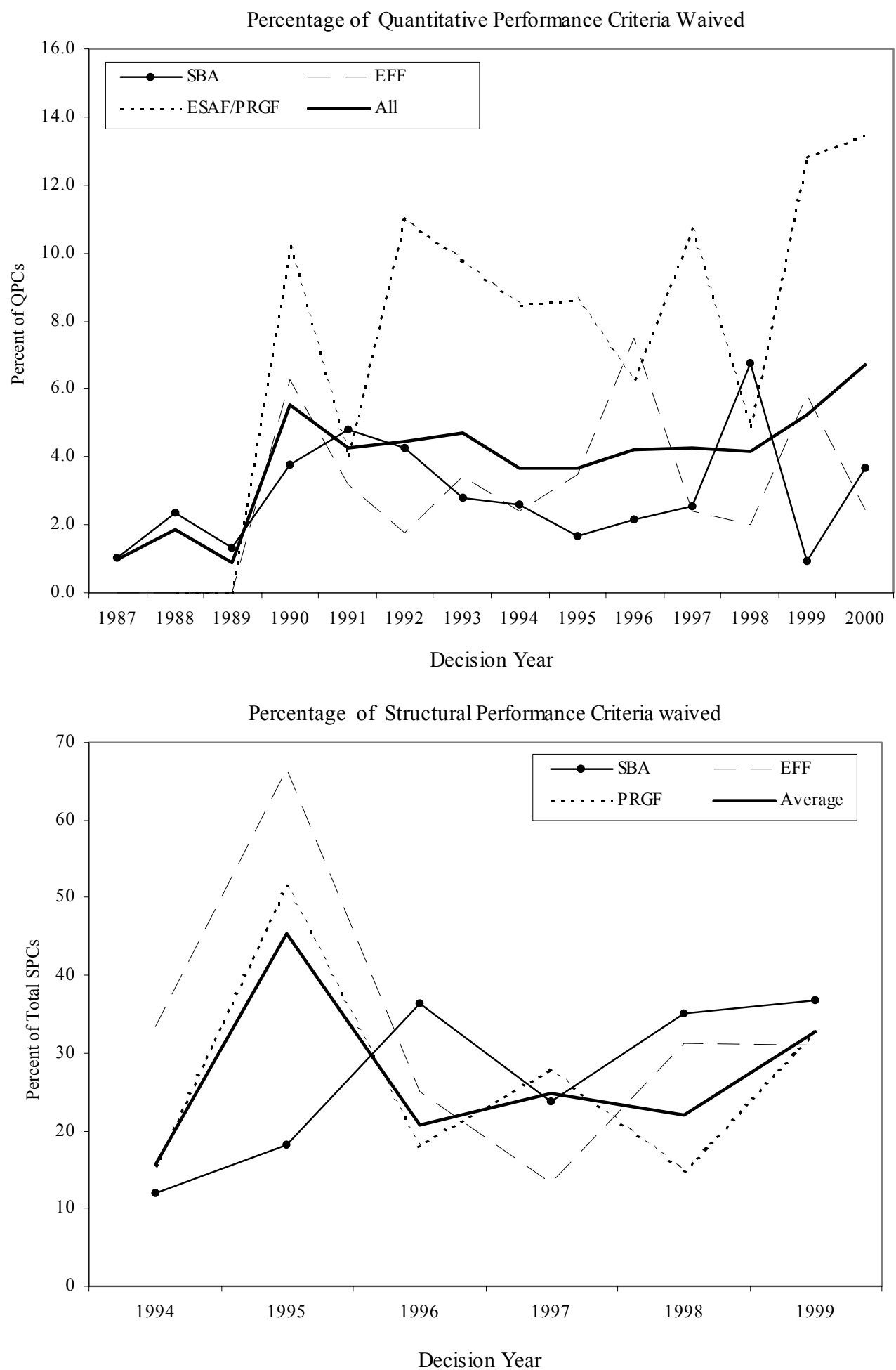

Source: Staff es timates. 
47. Similarly, the results showing that structural performance criteria are much more likely to be missed and then waived than quantitative performance criteria should also be treated cautiously. For one thing, quantitative performance criteria are typically set with margins in relation to the baseline and if these margins are set wide enough the PCs are unlikely to be missed. Quantitative PCs also often have automatic adjusters that take account of developments such as a shortfall of external financing, reducing the need for waivers. Second, the linkage between different macroeconomic PCs in the financial programming framework implies that the nonobservance of one macroeconomic PC is more often associated with nonobservance of others, making it less likely that a waiver can be granted unless there is substantial corrective action; failure to implement a structural PC is more likely to be an isolated event that can be waived. ${ }^{32}$ Another consideration, reflecting the legal mechanisms in place, is that in SBAs and EFFs, quantitative performance criteria are cumulative (i.e. relevant only for the most recent test date preceding the purchase), so if they are missed at one test date and not waived and then either observed or waived at a subsequent test date, purchases associated with both test dates would become available. Neither structural nor quantitative PCs under ESAF/PRGF arrangements have this cumulative property. $^{33}$

48. With these caveats in mind, there are three possible explanations for the apparent greater incidence of waivers for structural than for macroeconomic PCs. One is that structural PCs are inherently subject to greater uncertainty in their implementation, due to the vagaries of the political process involved in bringing them to completion. A greater incidence of waivers for structural PCs for this reason would be consistent with fully appropriate use of PCs and waivers. A second possibility is that structural PCs are in practice being applied to aspects of the authorities' agenda that, while important to program objectives, are expected to be the most difficult to implement. A third possibility is that structural PCs are more likely than macroeconomic PCs to be included in cases in which they are not really critical for a program's macroeconomic objectives - for instance, to push countries to undertake reforms that are considered desirable but are not key to the macroeconomic outlook, or perhaps to make a program appear stronger from the viewpoint of the Executive Board or the markets.

${ }^{32}$ In addition, each quantitative PC has multiple test dates while structural PCs usually have only one test date; multiple test dates mean that there are more opportunities for the PC to be breached, but this affects both the numerator and denominator of the incidence of breaches.

${ }^{33}$ This difference is in part a reflection of difference in the frequency of test dates for SBAs (quarterly) versus PRGF arrangements (semiannual). 
Figure 2. Structural Performance Criteria: Sectoral Distribution

SPCs (In percent of total)

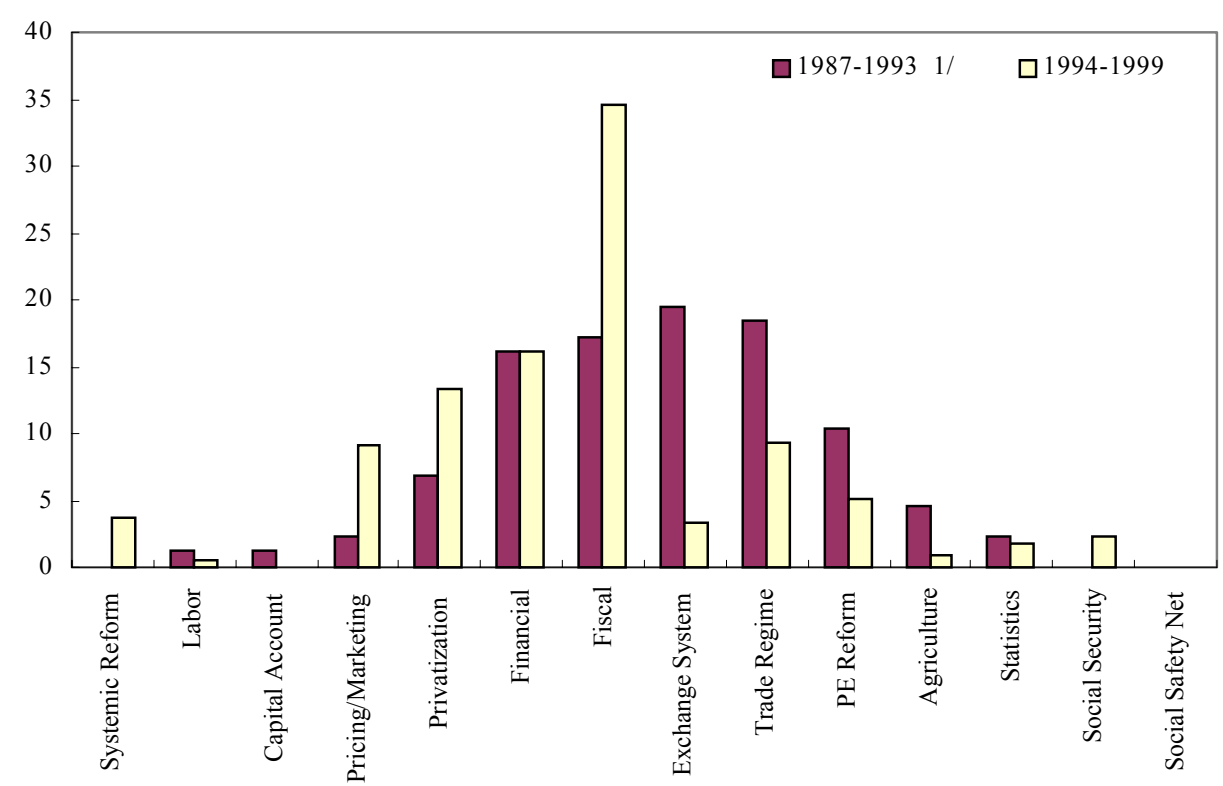

SPCs Waived (In percent of sectoral total)

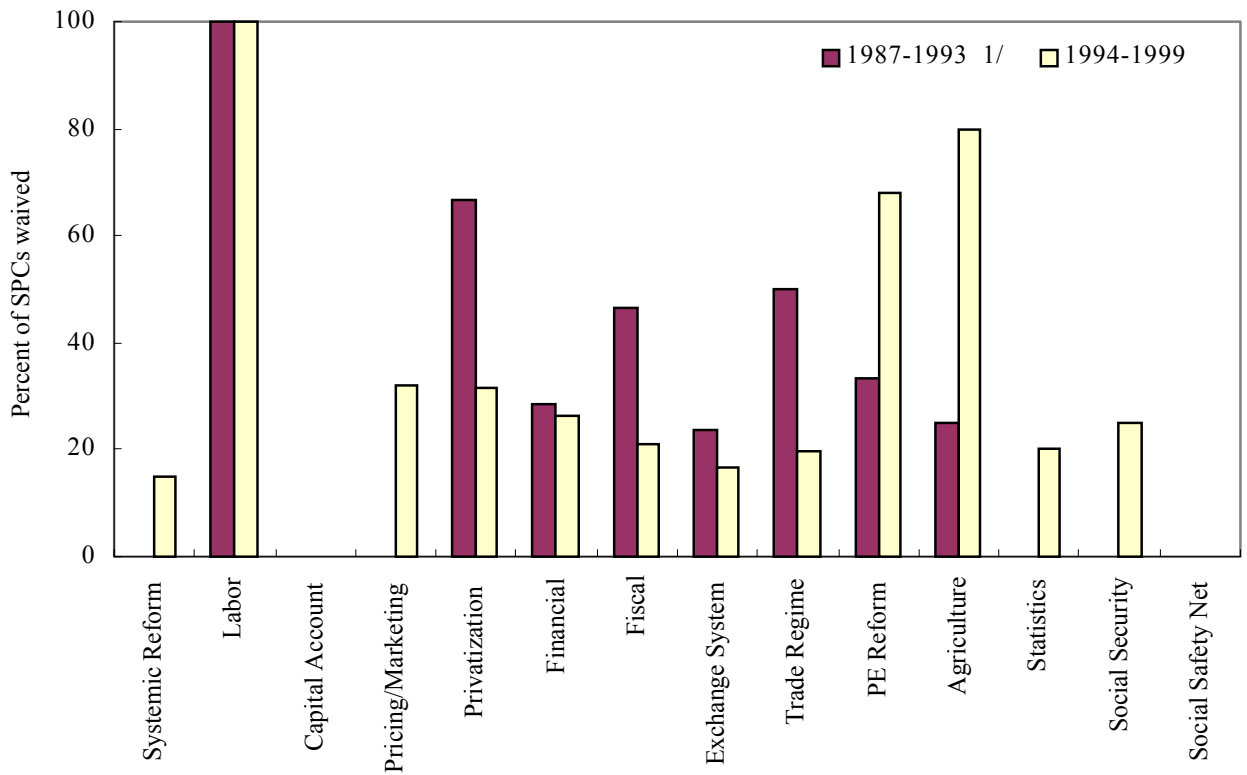

Source: MONA database; and program documents.

1/ Total number of structural performance criteria for 1987-1993 include only PCs on approval or, in the case of ESAF arrangements, at the start of each annual program. 
The latter use of structural PCs would raise concerns over the appropriateness of conditionality and program design; it would make it more likely that the policy measures would not be implemented, and that more likely that, in the event that they are not implemented, waivers would be granted.

49. In assessing the application of waivers more generally, it is also relevant to consider the concentration of waivers across countries. It is striking that the top 10 countries accounted for close to half of all quantitative and structural PCs waived in standby and extended arrangements in 1987-93, and more than a third of those in 1994-2000. ${ }^{34}$ Corresponding statistics for structural PCs alone are less meaningful, simply because of the much smaller number of SPCs in programs. ${ }^{35}$ Nevertheless, the record suggests that, at least in a few cases, a large proportion of SPCs are waived in countries that have chronically weak performance. But at the same time, it is noteworthy that some countries that had large proportions of SPCs waived - such as Korea (25 percent) or Bulgaria (60 percent) - had programs that turned out successfully after shaky starts. ${ }^{36}$

50. It is also useful to examine the reasons given for recommending waivers. A preliminary investigation of the reasons for waivers of the past decade indicates that some 80-85 percent were due to reasons other than minor/technical factors or exogenous developments, suggesting that the majority were the result of policy slippages. This does not, of course, indicate to what extent such policy slippages were offset by corrective action, and whether the corrective action was actually undertaken or only promised.

51. Thus, the view that waivers have in some instances been used beyond their intended role of adapting a viable program to changing circumstances cannot be ruled out although it is not clear how widespread this use has been. The experience with waivers may argue for somewhat greater caution in program design and selectivity in the use of Fund resources, particularly where the authorities' commitment to implementation is in question.

52. The streamlining of structural conditionality may be expected to result in a smaller percentage of structural PCs waived, for two reasons. First, taking better account of the need for ownership should increase implementation rates. Second, focusing conditionality on those

\footnotetext{
${ }^{34}$ Note that these figures are not normalized for the length of time different countries spent in programs or for the numbers of PCs in those programs, and so do not permit comparisons among countries.

${ }^{35}$ In effect, there is a "law of small numbers" problem. For instance, many programs may have only one structural performance criterion which, if missed and waived, immediately gives a 100 percent waiver rate.

${ }^{36}$ Moreover, in the case of Korea, all measures specified in the waived structural PCs were eventually implemented.
} 
measures that are critical to program objectives would make it less likely to find a basis for continuing the program notwithstanding the non-implementation of these measures. At the same time, there will continue to need to be a certain number of waivers for their intended purpose of dealing with changing circumstances or programming errors, as well as the policy slippages that would arise even if there is a reasonable degree of realism in program design.

\section{B. Prior Actions}

53. The role of prior actions as a tool of conditionality has also evolved over time. In the discussion of the 1978 review of conditionality, Executive Directors noted that in situations of protracted imbalances, it was very difficult to design a credible program unless the ground for it had been laid by prompt adoption of certain measures. To formalize these conditions, the 1979 Conditionality Guidelines stated that "a member may be expected to adopt some corrective measures before a stand-by arrangement is approved by the Fund, but only if necessary to enable the member to adopt and carry out a program consistent with the Fund's provisions and policies.”( $(77)$. Over time, however, prior actions began to be used more widely, "to ensure that the program has the necessary foundation, and-particularly where there is no established track record or only a weak one - to demonstrate the authorities' determination and political will to implement the program as formulated.",37 Moreover, in many cases countries have been expected to implement prior actions before a program review can be completed: in some cases, this means implementing measures that were to have been implemented by that time under the program originally envisaged, and in other cases to compensate for deficiencies in implementation. ${ }^{38}$

54. This role of prior actions in alleviating doubts about past performance can be seen as a form of signaling. This signaling role can be seen in two ways. One is that putting in place strong, difficult-to-reverse reforms at the beginning of a program can strengthen confidence. A second is that implementation of a critical mass of reforms at the outset can signal the authorities' determination to implement the rest of the program. The latter view would imply that prior actions are being used as a tool of selectivity, to distinguish between those countries that are truly committed to implementing the program and those that are only prepared to pay lip service in order to receive the Fund's financing. But to play this role, the prior actions must be such that a government that is not genuinely committed to

${ }^{37}$ Prior Actions - Fund Policy and Practice, EBS/96/164.

${ }^{38}$ Prior actions are sometimes compared with outcomes-based conditionality. They are similar in both requiring that some policy have been carried out before financing is provided. But PCs also have this feature; the only difference is that a PC is established further in advance. Where prior actions often differ from outcomes-based conditionality is that they are often applied to very specific policy actions, whereas outcomes-based conditionality by definition pertains to somewhat broader outcomes. 
implementing the program would rather forego the Fund's financing than implement these prior actions, whereas a government that is committed would be willing to implement them. It is not clear how often this requirement is satisfied in practice; it is not easy to establish this on the basis of observed variables, even ex post. The obvious question is then whether prior actions are being used effectively - be it to put in place reforms that enhance prospects for program implementation or as a tool for screening out those countries that are unlikely to implement a program that the Fund can support-or whether on the contrary, they are being used to justify providing financing to precisely those countries, possibly as well as trying to ensure that certain reforms are accomplished, even if the program soon goes off-track.

55. This argument can be considered in the light of evidence on the use of prior actions. The number of prior actions per program year rose tenfold from an average of less than 0.5 in 1987-90 to more than 5 in 1997-99. At the same time, the increase in the median number of PAs was less dramatic than in the mean-from 0.3 to 1.5 per program year-reflecting the wide dispersion across programs in the use of prior actions, with some large outliers. ${ }^{39}$

56. Information provided by mission chiefs on a sample of individual programs help shed light on these issues. ${ }^{40}$ They provide some illustrations of the use of prior actions: to ensure essential policy changes in difficult or crisis conditions (such as banking sector reforms in Yemen, Bulgaria, Nicaragua); to establish a track record at the outset of the programs (Bulgaria, Mongolia); or to buttress credibility following policy slippages in either the previous or current arrangement (Pakistan, Mongolia) - see Box 5. Preliminary results of an empirical analysis of the determinants of prior actions in programs approved during the period 1993-99 shed further light on the experience. The regression analysis, using data for all countries that had at least two Fund-supported programs during the period 1993-99, relates the number of prior actions in a given program to several explanatory variables, including the number of prior actions and the score on the structural measure implementation index in the country's previous program (Annex II). The regression indicates that programs in countries that had a low structural implementation score in their previous program, tend to have a higher number of prior actions in their current program. This accords with the intuition, and the survey results, that prior actions are used in countries that have previously weak track records.

${ }^{39}$ Moreover, since the issuance of the Interim Guidance Note on Structural Conditionality there has been a significant paring of structural benchmarks but no clear trend toward fewer prior actions. See Streamlining Structural Conditionality-Review of Initial Experience (SM/01/219, July 12, 2001).

40 This information was gathered through a questionnaire sent to the mission chiefs of the following 12 countries, evenly distributed across IMF Departments: Albania, Bulgaria; Uganda, Rwanda; Pakistan, Yemen; Kyrgyz Republic, Ukraine; Nicaragua, Uruguay; Mongolia, Philippines. 
57. Turning to the second question - whether prior actions have helped establish track records and contributed to the likelihood of the program's success - the evidence is not encouraging. A second (probit) regression was estimated relating the likelihood of a program stoppage to the number of prior actions in the current program (controlling for the implementation score in the predecessor program). The results indicate that programs with more prior actions are neither more nor less likely to suffer from a program stoppage. ${ }^{41}$ These results, while preliminary, suggest that prior actions have limited value in establishing a basis for successful implementation or in discriminating which countries are prepared to make a break from their past track record.

58. But these averages reflect a wide diversity of individual country experiences with the use of prior actions, as some countries with numerous prior actions turn out to be strong while others have had chronic weaknesses in implementation (Table 1). ${ }^{42}$ They include, in particular, several transition countries which, during the 1990s, faced an urgent need for reform in many areas at a time when many institutions were being created or strengthenedwhat in many cases amounted to an institutional vacuum combined with poor governance and weak ownership. In countries that are genuinely committed, prior actions provide a means for the authorities to crystallize and front-load their programs. In the chronic weak performers, prior actions may play a much less satisfactory role, seeming to justify the Fund's financing or serving as a vehicle for the Fund to bring about some reforms even though the program is likely to go off-track. In the latter case, the central problem is not with the use of prior actions, but with the continued provision of financing to countries that are not expected to carry out an acceptable policy program. This argues for adhering more strictly to the existing guidance that prior actions should be used parsimoniously. ${ }^{43}$ If a program can only proceed on the strength of very numerous prior actions, it should be questioned whether the program should receive the Fund's financing, or whether this financing should be delayed until doubts about implementation have been resolved. (At the same time, the diversity of experience discussed would argue against strict numerical limits on prior actions.)

${ }^{41}$ Of course, this is not the only indicator of a program's success. For instance, the structural conditions implementation score can be related to the number of prior actions in the current program. Implementation of structural conditions (excluding the prior actions themselves) turn out not to depend significantly on the number of prior actions in the program, consistent with the results obtained for program stoppages.

${ }^{42}$ Since the prior actions are normalized by the duration of the arrangement, they do not always equal whole numbers in stand-by cases whose lengths are measured in months (e.g. a program running for 14 months would be normalized as 1.2 years).

${ }^{43}$ See Prior Actions-Fund Policy and Practice (EBS/96/164). 


\section{Box 5. Survey Results on the Use of Prior Actions}

A sample of 12 mission chiefs was asked how prior actions had been used in their country cases. The first purpose of prior actions is to undertake corrective policies deemed necessary for the country to adopt and carry out the program. For example, in Yemen, a prior action was Cabinet approval of amendments to banking law to strengthen supervision in the face of banking system weaknesses. In Bulgaria, prior actions included the appointment of a director of the Deposit Insurance Fund to ensure its set up and initiating a management contract to improve the operations of one of the country's largest banks. In Nicaragua, prudential bank measures were invoked as prior actions to discourage additional short-term borrowing.

Bulgaria and Mongolia present typical cases of the need to establish a track record through the use of prior actions. At the beginning of Bulgaria's EFF in 1997, following on from weak performance under previous programs, 13 prior actions were formulated, ranging from the removal of tax preferences and improving the efficiency of the large taxpayers office to adopting an action plan to phase out subsidies. At the outset of Mongolia's arrangement under the PRGF in 1997, 19 prior actions were requested on speeding up the privatization process, setting hard budget constraints on public enterprises, and acting swiftly on bank restructuring. Both these countries were in transition from centrally planned to free market and rapid progress over a broad range of structural reforms was viewed as important to signal the government's intentions at the outset - which could best be achieved through setting prior actions.

Prior actions were also used to buttress credibility following policy slippages in either the previous or current arrangement. For instance, in the most recent programs of the Kyrgyz Republic, Pakistan and the Philippines, numerous prior actions were set in order to limit the likelihood that interruptions and delays in previous programs would be repeated. At the outset of Albania and Yemen's most recent PRGF programs the number of prior actions was moderate, but because of implementation delays, many additional prior actions were established during the course of the programs; through early 2001, the cumulative number of prior actions was 57 for Yemen and 29 for Albania.

The need to establish credibility may be all the more important in cases where the country did not complete the previous program. In Rwanda's case, six prior actions - all in the fiscal area-were included in the third year of the PRGF arrangement in order to ascertain the government's commitment to the program following the expiration of the second year of the arrangement in late 2000. In Ukraine, 30 prior actions were implemented at the outset of the most recent EFF program to demonstrate the authorities' commitment following the failure of the previous program. Many of these measures were in the area of fiscal policy, designed to address weaknesses in the fiscal situation that had led to the previous stand-by arrangement going off-track. Following the inability to bring Nicaragua's previous ESAF arrangement to the Board on account of disagreements on the implementation of prior actions, a new ESAF arrangement was negotiated in 1998. To bolster the credibility of the new program, 10 prior actions were implemented in the areas of public sector restructuring, privatization, legal and financial system reform, and trade policy. Subsequently, an additional 8 prior actions were added to ensure that conditions for the financing of the program would materialize. 
59. On average, the use of prior actions should decrease as conditionality is streamlined and national ownership of programs is strengthened, both as prior actions are limited to those needed to implement the program successfully and as there should be fewer cases in which numerous prior actions are used to make up for weak ownership. Greater selectivity in the use of Fund resources would likely also lead to a reduction in the use of prior actions.

60. A further issue concerns the manner in which the Executive Board is kept informed. The 1979 Conditionality Guidelines stipulate that where a program includes prior actions "the Managing Director will keep Executive Directors informed in an appropriate manner of the progress of discussions with the member" ( $\mid 7)$. In practice, this is typically done informally, through the Country Matters sessions and through informal briefings of the Board. Moreover, under the revised misreporting policy, prior actions are incorporated into and expressly identified in arrangements (albeit after the fact of their implementation). ${ }^{44}$ Some Executive Directors have suggested that the provision of such information should be formalized by circulating a periodic information note reporting on countries in the process of program discussions, indicating which prior actions have been agreed between staff/management and the member.

61. While a timely dialogue between Executive Directors could be helpful, particularly in cases in which some prior actions may be contentious, formal reporting on such prior actions in the midst of program discussions could have some drawbacks for the borrowing member country. First, program design and conditionality evolve in the course of discussions between the staff and the authorities, with important tradeoffs, such that shortfalls in one policy area are often offset by strengthened policies in others to achieve the overall macroeconomic objectives of the program. Requiring the Board to be formally notified of the prior actions before these discussions have been concluded would tend to make the staff's position unduly rigid, undermining the staff's and authorities' ability to negotiate the strongest possible, and best-owned program, particularly in the face of less-reform minded interest groups. Second, it would be difficult for the Executive Board to make a judgment on the appropriateness of particular prior actions without the context of the overall program design, and evolution of program discussions - in effect, a pre-review of the entire program or review, prior to completing discussions with the authorities. This suggests that it may be preferable to make more systematic use of current procedures under which management keeps the Board abreast of impending and ongoing program discussions through country matters sessions or other informal channels. These channels permit a dialogue between Management and the Board in cases where the program entails particularly contentious policy choices.

${ }^{44}$ See Concluding Remarks of the Acting Chairman-Strengthening the Application of the Guidelines on Misreporting, Executive Board Meeting 00/77, July 27, 2000 (BUFF/00/129, August 4, 2000). 
Table 1. Programs with more than 10 prior actions in each year (number of prior actions per program year)

\begin{tabular}{|c|c|c|c|}
\hline Country & Program Type & Initial Year of Program & Number of Prior Actions \\
\hline Ukraine & SBA & 1997 & 45.0 \\
\hline Bulgaria & SBA & 1997 & 41.7 \\
\hline Ukraine & $\mathrm{EFF}$ & 1998 & 38.0 \\
\hline Russia & $\mathrm{EFF}$ & 1996 & 25.0 \\
\hline Belarus & SBA & 1995 & 21.0 \\
\hline Romania & SBA & 1999 & 17.1 \\
\hline Yemen & PRGF & 1997 & 16.0 \\
\hline Egypt & SBA & 1996 & 15.5 \\
\hline Indonesia & SBA & 1997 & 15.0 \\
\hline Russia & SBA & 1999 & 14.3 \\
\hline Haiti & SBA & 1995 & 14.0 \\
\hline Bulgaria & SBA & 1996 & 12.4 \\
\hline Mongolia & PRGF & 1997 & 12.3 \\
\hline Venezuela & SBA & 1996 & 12.0 \\
\hline Cambodia & PRGF & 1999 & 11.0 \\
\hline Armenia & PRGF & 1996 & 10.3 \\
\hline Moldova & EFF & 1996 & 10.3 \\
\hline
\end{tabular}




\section{Program Reviews}

62. Program reviews are the most flexible element of the Fund's conditionality. ${ }^{45}$ Program reviews typically serve several distinct, albeit related, purposes. First, they provide an opportunity to take stock of program implementation, on the basis of a wide range of available information and extensive discussions with the authorities, and examine the reasons a program may be off-track - which may include policy slippages and exogenous shocks. This assessment may take note of progress in relation to structural benchmarks, which serve as indicators on the basis of which progress will be assessed rather than as conditions in their own right. Second, once such factors have been identified, the review may be used to reach an understanding on corrective policies. Third, reviews provide an opportunity to specify future performance criteria and structural benchmarks that could not be set at the outset of the arrangement and to modify existing criteria if necessary.

63. Program reviews have been increasing in importance as macroeconomic relationships have become more uncertain with capital market globalization, heightening the need for fixed quantitative targets to be complemented with assessments based on a wider set of information. The Fund's involvement with transition economies, where macroeconomic relationships were more difficult to establish, also militated in favor of more frequent reviews. Another factor accounting for the rising importance of reviews is the increased importance of structural reforms in Fund-supported programs; the substance of structural reforms typically needs to be assessed from the broader perspective that a review permits, not simply in relation to pre-set targets.

64. The importance of reviews is likely to increase still further as other aspects of conditionality_PCs and PAs - are streamlined. Policies in some areas that are important to the objectives of Fund-supported programs over the medium term but where the timetable is not closely linked to the macroeconomic framework may appropriately be monitored through program reviews. As the Fund comes to place greater reliance on program reviews in lieu of PCs and PAs, it should more often occur that the Fund fails to complete a review even when all PCs are satisfied. ${ }^{46}$

${ }^{45}$ The greater flexibility of reviews corresponds to greater discretion by the Fund and correspondingly weaker assurances to the member, hence the need to be as clear as possible in delineating the focus of reviews. See Conditionality in Fund-Supported Programs-Policy Issues (SM/01/60, Supplement 1, February 20, 2001).

${ }^{46}$ While, in principle this can happen under existing practice, in most cases when the forward-looking assessment of policies in a review suggests that the program is not on track to meet its objectives there is also at least one breached PC to provide further justification for suspending financing. 
65. Which policies are suitably monitored through reviews depends not only on the nature of the policy but also on the overall context of the program. As an example, a recent staff seminar discussed the application of conditionality to privatization. ${ }^{47}$ In this seminar, it was noted that privatizations differ considerably in their role in Fund-supported programs. In some instances, the privatization and restructuring of some loss-making state enterprise may be needed to staunch a hemorrhage of public funds; in such cases, it may only be prudent to commit the Fund's resources if privatization is implemented on a strict timetable. In other cases, however, privatization is part of a broader strategy of establishing a functioning market economy which is essential to sustainable growth over the medium term, but where the processes by which privatization are carried out is very important in achieving gains in growth. In such a situation, establishing specific timetables and numerical targets may be counterproductive, but the Fund, in committing its financing, needs to be sure that progress is being made with a well-designed and transparent process. In such cases, program reviews may play a vital role.

66. The growing importance of reviews makes it all the more important to delineate the scope of program reviews clearly so that there is no undue weakening of assurances to member countries regarding the conditions under which they will continue to have access to Fund resources. In addition to the requirement that reviews be limited in scope, there is a presumption against reviews' being used to strengthen program objectives or to escalate conditionality, although in some cases policies may need to be strengthened where the country's economic situation or international context changes in unexpected ways.

67. Another important issue concerns the appropriate frequency of reviews. At a very high frequency, such as monthly, there is a risk that reviews become a vehicle for micromanaging a country's economic policies and create an additional administrative burden that strains the authorities' capacity to implement their program. Moreover, given the short-term volatility in many economic data, very frequent reviews may have little value added as they may provide little sound basis for prescribing corrective action. Conversely, too lengthy a period between reviews may delay corrective policies when a program is going off track, with a consequent risk of major deviations.

68. In general, these considerations have been reflected in the choice of the frequency of reviews. The existing operational guidelines on reviews set semi-annual reviews as the norm for SBAs. ${ }^{48}$ In practice, however, quarterly reviews have often been established for SBAs,

${ }^{47}$ This seminar, including Fund mission chiefs as well as privatization specialists from the World Bank and academic experts, was held at Fund headquarters on July 12, 2001. See IMF Survey, September 3, 2001.

${ }^{48}$ The Operational Guidelines on Reviews state that, "Every effort should be made to include performance criteria initially for as much of the 12-month period of the Fund arrangement as possible... it would be reasonable to expect that, as a normal rule, performance criteria would 
with some increase in the frequency of reviews in recent years (Figure 3). In certain acute crisis cases (such as the Asian crisis countries in late 1997 and early 1998, or Turkey in 2001), arrangements have been subject to reviews of monthly or higher frequency, on the basis that in the context of volatile capital flows there is considerable scope for the program to go seriously off track within a comparatively short time period and that stronger safeguards are needed in light of the scale of resources committed in such cases. In PRGFs and many EFFs, semi-annual reviews have been the norm, reflecting the longer-term nature of the adjustment and longer reporting lags in macroeconomic data which makes very frequent reviews less useful.

69. To the extent that the present reform of conditionality puts greater emphasis on strong national ownership, reviews should, on average, become less frequent, with semi-annual reviews the norm. At the same time, more frequent reviews are likely to continue to be needed in some cases - notably in volatile situations such as in crises, or in cases of weak ownership - to provide adequate safeguards for the Fund's resources. Greater use of resultsbased conditionality and floating tranches, as discussed earlier in the paper, would tend to change the nature of reviews. First, evidence on outcomes may be more complex and accumulate over a longer period than evidence on policy actions, and this would tend to increase the importance of reviews. But on the other hand, there should be decreased reliance on program reviews to reach agreements on adjustments that should be made to achieve the objectives of the program, in the event that circumstances change: instead, the country would be responsible for making such adjustments. Policies attached to floating tranches would be assessed in program reviews only if the country is requesting release of a particular tranche on the grounds that they have been implemented. Finally, since both outcomes-based conditionality and floating tranche disbursements imply a longer-term horizon in assessing implementation of structural reforms, they would tend to go along with less frequent reviews.

\section{Conclusion}

70. This examination of the tools of conditionality underscores that there are good reasons for the items in the existing toolkit. Performance criteria with the possibility of

be included initially which would govern purchases over a period of at least six months of the arrangement. Where this minimum period is not met, the staff report would include a full explanation of the underlying reasons." 
Figure 3. Distribution of Review Frequencies in Fund-Supported Programs, 1992-2000 1/,2/,3/

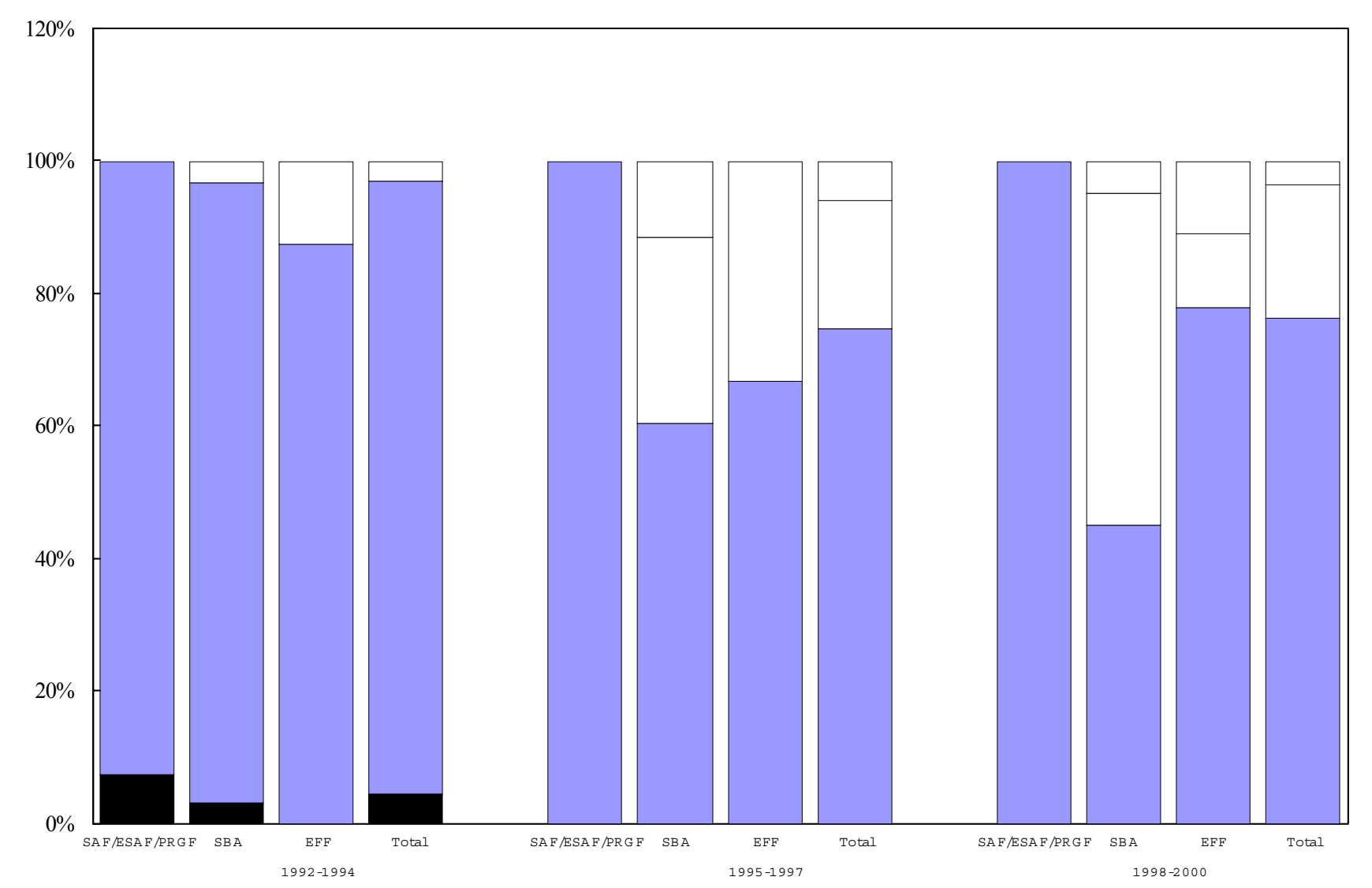

$\square$ annual $\square$ semiannual $\square$ quarterly $\square$ other

Source: MONA Database

1/ For 1992 and 2000 only programs reflected in MONA database are counted.

2/ For Korea review frequency is considered quarterly, ignoring few biweekly reviews at the beginning of the program.

$3 /$ In some cases "semi-annual" includes reviews that were scheduled at less than six month intervals. 
waivers, prior actions, and program reviews, usually guided by structural benchmarks, provide a combination of clarity in delineating the policies that the country is expected to follow as the basis for continued IMF financing and flexibility in allowing for unforeseen circumstances and for the inadequacy of fixed performance targets. In some instances, however, the inappropriate use of these tools may be symptomatic of deeper weaknesses in program design, ownership, and selectivity, which need to be addressed directly rather than through a reorganization of the toolkit.

71. The balance among these tools may also change as conditionality is reformed. In particular, to the extent that the Fund's conditionality is refocused and streamlined and that the Fund is more successful in ensuring that its financing goes toward programs that are realistically designed and nationally owned,

- $\quad$ There would tend to be somewhat fewer waivers. This should occur both because, with stronger ownership and more realistic program design, fewer PCs should be missed; and because those PCs that are established should be critical to program objectives, implying that it would be more difficult to make a case for waivers in the event that these PCs are missed (unless vigorous corrective action is taken).

- The numbers of prior actions would tend to decrease. This should be both because prior actions will be included only to the extent that they are critical to the macroeconomic objectives of the program, and because they are less likely to be used to compensate for weak ownership.

- $\quad$ Program reviews are likely to increase in importance, but they should be better focused on the policy objectives of the program, with structural benchmarks more closely linked to the scope of the review. The existing guidelines, under which reviews should be semiannual unless there is a clear reason for them to be more frequent, should be adhered to.

\section{Presentation of Conditionality in Fund Documents}

72. It is also important to ensure that the nature and boundaries of the Fund's conditionality are presented clearly in all Fund documents. Steps in this direction have already been taken. In March 2001, the Executive Board requested that Letters of Intent should make it clear which aspects of the authorities' overall policy agenda are subject to the Fund's conditionality. Moreover, beginning in June 2001, staff reports have contained a standardized box indicating the coverage of structural conditionality, the rationale for the areas covered and those not covered, and the division of labor with the World Bank and other agencies.

73. In addition, it would be useful for the LOI and Staff Reports for the use of Fund resources to present all the elements of conditionality in one place in a format that could easily be compared across countries. In line with the discussion of the modalities of 
conditionality in this paper, all staff reports could present a single standardized table showing (a) macroeconomic and structural performance criteria, (b) prior actions, and (c) the areas on which program reviews will focus, indicating any structural benchmarks against which performance will be assessed. ${ }^{49}$ Such a presentation would be particularly useful given that Staff Reports are now in many cases being published.

\section{ISSUES FOR DISCUSSION}

74. Directors may wish to focus their interventions on the following issues:

- Would Directors favor a shift toward a more outcomes-based approach to conditionality? What do they see as the balance of advantages and risks to such a shift?

- Do Directors approve the use of floating tranche disbursements for some elements of structural conditionality - and if so, under what circumstances?

- Do Directors agree that the existing tools of conditionality remain broadly appropriate? Directors may also wish to comment on the concerns discussed, to the effect that the element of flexibility associated with these tools has sometimes been misused to make up for weaknesses in selectivity and ownership. They may wish to discuss how the use of these tools is likely to evolve as conditionality is reformed.

- $\quad$ Do Directors agree that the Fund should use prior actions more sparingly, in view of their apparently limited usefulness in compensating for a weak track record? Do Directors agree to make more systematic use of present practice under which the Board is informed of prior actions through informal Board meetings?

- Would Directors be willing to see greater reliance on reviews as other aspects of conditionality are better focused and streamlined? Do Directors agree that the presumption should continue to be that reviews are semiannual, but that in some cases more frequent reviews may be needed to safeguard the use of the Fund's resources?

\footnotetext{
${ }^{49}$ Existing practice is to include a table listing all performance criteria, prior actions, and structural benchmarks; the proposed innovation would be to indicate the areas to be covered in program reviews (and relate structural benchmarks explicitly to those areas).
} 


\section{Financing Assurances and Implicit Conditionality}

75. A clear division of labor and enhanced cooperation with the World Bank and other agencies are viewed as an important element of streamlining Fund conditionality, permitting the latter to focus on those policies that are critical to achieving the macroeconomic objectives of the program and to be applied particularly sparingly outside the Fund's core areas of responsibility.

76. It is also possible, however, that a country would need to comply with conditions established by some other institution in order to receive Fund financing, even though the measure does not appear as an explicit condition under the Fund program. The latter possibility, which may be termed "implicit conditionality," stems from the Fund's policy on financing assurances, requiring that only arrangements that are fully financed can be supported by Fund resources (see Box 6). ${ }^{50}$ As a result of the need for such assurances, the conditions for disbursements established by other donors and creditors at the time of approval of new arrangements may de facto become requirements for the disbursement of Fund resources, even though they are not included as explicit Fund conditionality. Thus, while formally there is no cross-conditionality, as the Fund's Executive Board remains fully accountable for decisions on the use of Fund resources, such decisions cannot but be influenced by fulfillment of the conditions needed to unlock the financing of other institutions.

77. This section discusses whether, and under what circumstances, such implicit conditionality is likely to arise. For this purpose, it is useful to distinguish between possible implicit conditionality at the time of approval of the Fund arrangement and that which may occur during the course of the program (at the time of reviews).

\section{A. Financing Assurances and New Arrangements}

78. The Fund's policy on financing assurances is intended to ensure that, on approval of a new arrangement, a program is fully financed (or, in the case of a multi-year arrangement, at least the first year is financed) - since otherwise the policy program is not feasible. The requirement is that the Fund not approve a new arrangement unless all the external financing required to close the financing gap has been secured, so that the member is assured of an adequate cash flow to finance its projected balance of payments (including allowing for a prudent buildup of reserves) without unduly compressing imports.

\footnotetext{
${ }^{50}$ The policy on financing assurances applies to official sources of financing only. Under the Fund's policy on financing assurances, it is possible to approve an arrangement without a completed financing package from private creditors. In these cases, and subject to certain safeguards, PCs would be quarterly until agreement has been reached with private creditors.
} 
79. This policy has important implications for potential implicit conditionality since countries - especially those with limited recourse to capital markets - may be required to satisfy conditions of other donors and creditors to secure financing from them. To the extent that the country is unwilling or unable to fulfill the conditions imposed by other donors and creditors, it needs either to find other sources of financing or to undertake additional adjustment.

\section{Box 6-The Fund's Policy on Financing Assurances}

The objective of the Fund's policy on financing assurances is to ensure that the Fund supported program "... is fully financed; that the financing is consistent with a return to viability and with the ability of the member to repay the Fund; that there is fair burden sharing; and that the program, if appropriately implemented and supported, would contribute to the maintenance or re-establishment of orderly relations between the member and its creditors." As such, financing assurances require not only that there is viable strategy to resolve a member's outstanding arrears where such exist, but that there is a sufficient financing scheduled over the program period which would close the financing gap, and hence the member would need not to resort to accumulating new arrears. In this process, the program takes account of all possible source of financing, and the planned change in reserves reflect, inter alia, the scheduled disbursements from multilateral and bilateral sources. The financing assurances policy allows Fund financing in the presence of arrears only if there are understandings that the arrears would be eliminated during the course of the arrangement.

${ }^{1}$ From Summing Up by the Chairman, Fund Involvement in the Debt Strategy, Executive Board Meeting 89/61, May 23, 1989, 89/89, pg, 3.

\section{B. Financing Assurances and Reviews}

80. The Fund's policy on financing assurances, and the implied conditionality, could also lead to program interruptions in the context of reviews. Here the situation is somewhat different from that at the time of arrangement's approval. In particular, a failure to meet the conditionality of another agency, and the resulting loss of financing, could result in an interruption of the Fund-supported program if it triggers a nonobservance of Fund performance criteria, such as those on the level of net international reserves or banking system credit to the government.

81. Such an interruption and a re-assessment of the program, including the possible need for additional adjustment or for support from other sources, would be appropriate if the shortfall in external support is significant and is not expected to be reversed relatively soon. On the other hand, if there are minor delays in implementing conditions of other agenciesand these conditions were not deemed sufficiently important to the program's macroeconomic objectives to warranted being included in Fund conditionality directly- then an interruption of the Fund arrangement would not be appropriate and could jeopardize the macroeconomic gains made under the Fund-supported program. 
82. Fund arrangements contain mechanisms to protect against such contingencies. First, the majority of Fund arrangements include adjusters to PCs, which allow modification of program targets in response to unforeseen events outside the authorities' control or events that are under the authorities' control, but for which timing and the exact magnitude involved are uncertain. Second, in the event that program targets are nevertheless missed, the staff can recommend waivers to permit the completion of reviews.

83. Most Fund programs include adjusters to performance criteria on net international reserves (NIR), net domestic assets (NDA), net credit to the government (NCG), and other relevant PCs with respect to unexpected shortfalls in external financing from the World Bank, and other multilateral and bilateral sources. They protect programs by accommodating the shortfalls without unduly affecting program objectives. ${ }^{51}$ They are a recognition of uncertainties associated with external financing, particularly its timing. Adjusters are triggered automatically when there is a shortfall in external financing. A further advantage of adjusters is that they allow the program to prespecify the policy response to deviations from program assumptions, while preserving the assurances to the country of being able to make a purchase in the absence of a review.

84. The design of adjusters and the policy response to shortfalls in external financing varies, depending on several country-specific factors. ${ }^{52}$ For example, in many cases the adjustment of PCs is allowed only up to a prespecified absolute limit, i.e. accommodating the shortfall in expected external financing up to this limit, whereas shortfalls exceeding the limit are expected to lead to policy adjustments in order to safeguard the attainment of program objectives and Fund resources. In some programs, PCs are adjusted by the full amount of the deviation ("dollar for dollar") from the expected financing (up to an absolute limit) or by a portion (in percent) of the deviation. ${ }^{53}$ The latter case ensures some adjustment effort from the outset of the financing shortfall.

${ }^{51}$ Typically, adjusters relax the target for international reserves and for net domestic assets by the amount of a shortfall in external financing, so that in the event of delays in receipts the country can maintain its spending plans. In some cases, adjusters are symmetric, applying to greater-than-programmed external aid or financing as well as to shortfalls; in other cases, they apply only to shortfalls.

${ }^{52}$ These factors include the level of international reserves, capacity to adjust budget in short term, the degree of openness of the economy and the private sector's access to international capital.

${ }^{53}$ The different types of design can be illustrated through the following examples. A full adjustment subject to an absolute limit could be specified as "The floor on the NIR PC will be decreased by the full cumulative amount of any shortfall in net external financing vis-à-vis the programmed level; the total downward adjustment of the NIR PC will be [US100 
85. Some arrangements, however, do not include adjusters to PCs, either because there is no room for less-than-full adjustment to a shortfall in external financing (e.g. because the programmed level of reserves is already critically low) or because financing from the World Bank or other multilateral agencies is not of sufficient importance to require allowing for delays.

86. The use of adjusters is not without disadvantages. Complex adjusters may make a program less transparent, in particular by disguising weak or unrealistic programs, including those with unrealistic projections of external financing. In particular, projections of aid receipts, based on donor commitments, have a systematic tendency to exceed outcomes. ${ }^{54}$ With the standard set of adjusters, a shortfall in receipts results in a downward adjustment of the PC for NIR and an upward adjustment of those for NDA and credit to government. More realistic aid projections in the first instance would have shown that these targets were in fact less ambitious than they appeared.

87. In cases where there are no adjusters, or the actual shortfall in financing is larger than the one accommodated by adjusters, and the PCs are missed, waivers may nonetheless be granted. The recommendation to grant a waiver could be based on: (i) the subsequent implementation of the policy action and disbursement of the said funds; or (ii) a judgment that the delay in financing does not endanger the program - as, for instance, where a lower level of reserve accumulation and/or greater recourse to other sources of financing is viewed to be acceptable. If the shortfall in financing were permanent, the Fund program can be modified to include additional remedial measures (perhaps in the form of prior actions) and the program targets can be adjusted, providing sufficient assurances that the new targets can be met to proceed with the arrangement.

88. To assess whether, in practice, adjusters to PCs have been sufficient to protect programs against temporary disruptions to external financing, the staff analyzed the design of performance criteria in a sample of 12 recent programs. ${ }^{55}$ The results are summarized in

million]". An adjuster allowing a portion of the deviation without an absolute limit could be specified, as "The floor on the NIR PC will be decreased by 80 percent of the amount of any shortfall in net external financing vis-à-vis the programmed level."

54 This tendency is documented in a recent working paper, "How Volatile and Predictable are Aid Flows, and What are the Policy Implications?" by Aleš Buliř and Javier Hamann (WP/01/167, October 2001).

${ }^{55}$ As above, the sample consists of Albania, Bulgaria; Uganda, Rwanda; Pakistan, Yemen; Kyrgyz Republic, Ukraine; Nicaragua, Uruguay; Mongolia, Philippines. 
Table 2. Nearly all the programs in the sample included adjusters, or the PCs were defined to accommodate external financing shortfalls. In a few of these cases, notwithstanding adjusters, delays in external financing still resulted in the need for waivers, but in none of these cases did delays in external financing alone lead to delayed completion of a review or an interruption to the program. ${ }^{56}$

\section{Conclusion}

89. To summarize, some element of implicit conditionality, especially at the time of program approval, would appear to be an inevitable counterpart to the Fund's policy on financing assurances. Nor is there any easy way of avoiding this, since the logic of program design requires that planned adjustment and available financing be sufficient to close the financing gap. Fund-supported programs should, however, be resilient to temporary slippages in the implementation of other agencies' conditions, in cases in which these were not deemed sufficiently important to the macroeconomic objectives to warrant being included in Fund conditionality. This resilience can - and typically is - achieved through the use of adjusters or, if necessary, waivers, although both of these tools have limitations which have been noted. This implies that the degree of implicit conditionality depends very much on an individual country's financing situation: in some cases, the Fund's financing may, in practice, virtually be determined in concert with the World Bank and other lenders, while in others the Fund's financing is more free-standing in nature. These considerations make it particularly difficult in many cases to clarify the boundaries of the Fund's conditionality.

${ }^{56}$ World Bank and other types of external program financing were treated equally in all programs, and therefore the discussion of the results below applies to all types of external financing. 
Annex Table 1. Explicit adjusters with respect to shortfall of external financing applicable to the following PCs

\begin{tabular}{|c|c|c|c|c|c|c|c|c|c|c|c|c|}
\hline & \multicolumn{3}{|c|}{ NIR adjustor } & \multicolumn{4}{|c|}{ NDA Adjustor } & \multicolumn{3}{|c|}{ Fiscal PC Adjustor 1/ } & \multirow[b]{2}{*}{ Waivers $2 /$} & \multirow[b]{2}{*}{ Delays $3 /$} \\
\hline & Used & $\begin{array}{c}\text { Full } \\
\text { adjustment }\end{array}$ & $\begin{array}{c}\text { Ceiling on } \\
\text { adjustment }\end{array}$ & $\begin{array}{r}\text { Used } \\
\\
\mathrm{a}\end{array}$ & $\begin{array}{c}\text { Full } \\
\text { adjustment }\end{array}$ & & $\begin{array}{c}\text { Ceiling on } \\
\text { adjustment }\end{array}$ & Used & $\begin{array}{c}\text { Full } \\
\text { adjustment }\end{array}$ & $\begin{array}{c}\text { Ceiling on } \\
\text { adjustment }\end{array}$ & & \\
\hline Albania & Yes & Yes & Yes & Yes & Yes & $4 /$ & Yes & Yes & Yes & Yes 5/ & No & No \\
\hline Kyrgyz Rep. & Yes & Yes 7 & Yes & Yes & Yes & 7/ & Yes $8 /$ & Yes & Yes 1 & Yes $10 /$ & No & No \\
\hline Mongolia & Yes & Yes & Yes 11/ & Yes & Yes & & Yes 11/ & Yes & Yes & Yes 11/ & No & No \\
\hline Nicaragua & Yes & Yes & Yes & Yes & Yes & & Yes & Yes & Yes & Yes & Yes & No \\
\hline Philippines & Yes & Yes & No & N.A. $17 /$ & & & & N.A. & $18 /$ & & No & No \\
\hline Ukraine & Yes & No; Yes 19 & No; Yes 19/ & Yes & No; Yes 1 & 19/ & No; Yes 19/ & Yes & Yes & No $20 /$ & No & No \\
\hline Uganda & Yes & Yes & Yes & Yes & Yes & & Yes & Yes & Yes & Yes & No & No \\
\hline Uruguay & No & & & No & & & & No & & & No & No \\
\hline Yemen & Yes & Yes & Yes & Yes & Yes & & No & Yes & Yes & Yes 21/ & Yes & No \\
\hline
\end{tabular}

Source: Staff Reports and Area Departments.

1/ Unless otherwise specified, the fiscal PC under the program is defined as net credit to the government.

2/ Waivers of performance criteria requested and granted due to shortfall in external financing.

3/ Delays in program due to shortfall in external financing.

4/ In the first year program, the adjustment was 50 percent of the shortfall. Subsequently, an absolute cap was introduced

5/ There was no cap in the first year of the program.

6/ Under a currency board arrangement Bulgaria does not have NIR and NDA PCs.

$7 /$ In the first year of the program, the cap wa s 50 percent of shortfall subject to a maximum of 10 percent of reserve money.

8/ There was no cap in the second annual program.

9/ The fiscal PC was changed to cumulative fiscal deficit of the general government starting with the second annual arrangement.

10/ There was no cap in the third annual arrangement

11/ Caps were introduced starting with the second annual arrangement.

$12 /$ In the first annual arrangement, net domestic financing of the budget was also a PC.

13/ The fiscal PC was net domestic financing of the budget.

14/ The PC was on NFA of the central bank.

15/ In addition to net credit to government, primary fiscal balance was also a PC. However, no adjustors for foreign financing were applicable to it.

16/ The NFA PC was missed partly due to shortfall in external financing (exchange market intervention and export shortfall were other factors) and waiver was granted.

17/ Philippines had a ceiling on base money.

18/ Ceiling on public sector borrowing requirement permits substitutibility of external and domestic financing

19/ In the early stages of the program, less-than-proportianal adjustment with no ceiling; later, proportional adjustment with a ceiling.

20/ In 2000, a fully proportional downward adjustment to the fiscal deficit PC with respect to shortfall in project financing was added.

21 / In the early stages of the program, no automatic adjustor applied to the fiscal PC. Instead, in the event of a shortfall of external financing, credit ceilings were to be reviewed taking into accout several factors, including budgetary effort to compensate for the shortfall. 


\section{Use and Effects of Prior Actions: A Statistical Analysis}

90. In order to gauge the use and effects of prior actions, a statistical analysis of all programs negotiated over the 1992-99 period was conducted.

\section{Use of Prior Actions}

91. The first regression examines the determinants of the number of prior actions in a program. Specifically, it relates the number of prior actions to the total number of structural conditions in the program (as a normalization); the number of prior actions and the implementation index of structural conditionality in the preceding program; an indicator of whether the government had recently changed; and the length of time the government had been in power. ${ }^{57}$ The total number of conditions and the implementation index were differentiated according to the type of Fund arrangement (stand-by, EFF, and PRGF). The estimation was conducted using GMM with a correction for first order autocorrelation and heteroscedasticity.

[1] No of conditions in stand-by progs $\quad 0.95 *$ No of conditions in EFF progs 0.53 * No of conditions in PRGF progs 0.16 *

[2] Lagged prior actions $\quad 0.18 * *$

[3] Lagged implementation index in stand-by progs $\quad-7.36 *$ Lagged implementation index in EFF progs $-3.35 *$ Lagged implementation index in PRGF progs $\quad-0.06$

[4] Time in power (logarithm) $\quad 1.24 *$

Change of government $2.25 *$

$\begin{array}{ll}\text { R squared } & 0.81\end{array}$

* Denotes significance at 5 percent levels; ** denotes significance at the 10 percent level.

57 The implementation index was calculated by giving the value 0,1 , or 2 to each condition depending on the speed at which it was implemented: no implementation (0), implemented with a delay (1), or implemented immediately (2). For structural benchmarks, a delay of 3 months was coded as a 2 . These values were then averaged across all conditions to generate a continuous variable between 0 and 2 . 
92. Not surprisingly, the number of prior actions is higher, the greater the total number of conditions. The number of prior actions in the current program is also positively related to the number of prior actions in the country's previous program and to the implementation index for the previous program.

93. Finally, turning to how characteristics of the borrowing country might affect the number of prior actions, the duration of the incumbent is found to have a significant effect and indicates that the number of prior actions rises with the length of period the government has been in office (although, since the variable is measured in logarithms, the effect levels off over time). This finding is consistent with the work of Dollar and Svensson ${ }^{58}$ who found that governments with longer spells in power were likely to be less committed to structural reforms. The dummy variable for the change in government is also significant, and indicates that programs in countries that had changes in government during the duration of a program had, on average, two additional prior actions. A possible explanation is that the commitment of a new government may be relatively unknown, and more prior actions may help establish this commitment. Therefore, although it is likely that a new government is more committed to reform, the uncertainty about its type appears to outweigh this consideration. Over time, as the uncertainty is resolved the number of prior actions decline only to rise again in countries with long-lasting governments. ${ }^{59}$

\section{Effects of Prior Actions}

94. Two further regressions were estimated to assess the effect of a higher number of prior actions on the program's prospects of success. The first uses probit estimation in which the dependent variable is the probability of a program stoppage. The explanatory variables are the number of prior actions, the country's implementation score in its previous programs, as well as various country characteristics (such as the quality of bureaucracy, the nature and stability of the government, etc.). The likelihood of a program stoppage is found to be related to the country characteristics. The number of prior actions is, however, found to have an insignificant effect on the probability of a stoppage: a program with a larger number of prior actions is no more - or less-likely to suffer a stoppage (column 1).

\footnotetext{
58 "What Explains the Success or Failure of Structural Adjustment Programs?" Economic Journal 110 (October 2000): 894-917.

${ }^{59}$ The turning point is at 6 years so that the number of prior actions in a country that has just changed government is equivalent to one that has been in office for 6 years.
} 
Prior actions

$0.02 \quad-0.01$

Total number of conditions

$-0.02 \quad-0.006$

Lagged implementations index

$0.33-0.02$

Democratic

$0.06 \quad-0.1$

Autocratic

Government instability

$-0.79-0.005$

Change of government

$1.24 * * \quad-0.46 *$

Quality of bureaucracy

0.32

$0.40 * *$

Quality of bureaucracy interacted with time in power

2.29

Time in power

$-1.45 *-0.02$

0.32

$0.24 * *$

Percent of correct predictions

$77 \%$

R-squared

0.2

95. Similar results are found when implementation scores for structural measures (excluding prior actions) are taken as the dependent variable. ${ }^{60}$ Such implementation scores are not significantly affected by the number of prior actions, controlling for the country's country's implementation score in its previous program (column 2).

${ }^{60}$ It is necessary to exclude prior actions from the implementation score, to remove the effect of the implementation rates of prior actions are, by their nature, higher than for other structural conditions. 